\title{
Regime switching in stochastic models of commodity prices: An application to an optimal tree harvesting problem
}

\author{
Shan Chen and Margaret Insley ${ }^{1}$ \\ Department of Economics, University of Waterloo
}

July 2010

\begin{abstract}
This paper investigates whether a regime switching model of stochastic lumber prices is better for the analysis of optimal harvesting problems in forestry than a more traditional single regime model. Prices of lumber derivatives are used to calibrate a regime switching model, with each of two regimes characterized by a different mean reverting process. A single regime, mean reverting process is also calibrated. The value of a representative stand of trees and optimal harvesting prices are determined by specifying a Hamilton-JacobiBellman Variational Inequality, which is solved for both pricing models using a fully implicit finite difference approach. The regime switching model is found to more closely match the behaviour of futures prices than the single regime model. In addition, analysis of a tree harvesting problem indicates significant differences in terms of land value and optimal harvest thresholds between the regime switching and single regime models.
\end{abstract}

JEL Classification: C63, C61, Q23, D81

Keywords: regime switching, optimal tree harvesting, mean reverting price, lumber derivatives prices, Hamilton Jacobi Bellman Variational Inequality

\footnotetext{
${ }^{1}$ Corresponding author: Department of Economics, University of Waterloo, Waterloo, Ontario, Canada, N2L 3G1. Phone: 519-888-4567, ext. 38918. Email: minsley@uwaterloo.ca
} 


\section{Introduction}

The modelling of optimal tree harvesting and the valuation of land devoted to commercial timber harvesting is an active research area in the academic literature. An ongoing challenge is how best to model the dynamics of timber prices in determining optimal harvesting strategies and in estimating the value of forested lands. Over the past two decades some researchers have modeled price as an exogenous factor described by a stochastic differential equation (see Thomson (1992); Plantinga (1998); Morck et al. (1989); Clarke and Reed (1989) for example). Others have used stand value (price of wood times quantity of wood), as the stochastic factor, abstracting from physical tree growth, such as in Alvarez and Koskela (2007) and Alvarez and Koskela (2005). The model chosen to describe timber prices can have a significant effect on optimal harvesting decisions and land valuation. The issue is therefore of importance to forest management, whether on publicly or privately owned land. There has been a trend over the last two decades to view commercial timber lands as a suitable asset to diversify the portfolios of large investors. Institutional investors in the United States have significantly increased their holdings of timberlands, giving an added motivation for a better understanding of timber price dynamics and investment valuation. ${ }^{2}$

Several specifications have been proposed in the literature for modeling stochastic lumber prices, including geometric Brownian motion (GBM), mean reversion and jump processes. A number of researchers have solved optimal tree harvesting problems analytically, assuming prices follow GBM. ${ }^{3}$ Some researchers have found that mean reversion rather than GBM provides a better characterization of lumber prices (Brazee et al., 1999). For commodities in general, it has been argued that mean reversion in price makes sense intuitively since any significant upturn in price will bring on additional supplies. Unfortunately it is difficult to conclude definitively whether the price of any particular commodity is stationary or not. As is noted in Insley and Rollins (2005) many different statistical tests exist, but none has been shown to be uniformly most powerful. The assumption of a price process other than GBM generally requires numerical solution of an optimal tree harvesting problem. This can present

\footnotetext{
${ }^{2}$ See Global Institute of Sustainable Forestry (2002) and Caulfield and Newman (1999) for a discussion of this shift in ownership.

${ }^{3}$ Examples are Clarke and Reed (1989) and Yin and Newman (1997).
} 
significant challenges particularly if the researcher chooses to model the growing forest stand in a realistic fashion over multiple rotations or cutting cycles.

An added complication is that for many commodities, price appears to be characterized by discrete jumps. A recent insight in the literature suggests that instead of modeling jumps, we may consider regime switching models, initially proposed by Hamilton (1989), to better capture the main characteristics of some commodity prices. Using a regime switching model, the observed stochastic behavior of a specific time series is assumed to be comprised of several separate regimes or states. For each regime or state, one can define a separate underlying stochastic process. The switching mechanism between each regime is typically assumed to be governed by an unknown random variable that follows a Markov chain. Various factors may contribute to the random shift between regimes, such as changes in government policies and weather conditions.

In this paper we investigate whether a regime switching model is a good alternative for modeling stochastic timber prices. For simplicity we assume the existence of two states or regimes. In line with Chen and Forsyth (2008), we calibrate a regime switching model with timber price as the single stochastic factor which follows a different mean reverting process in each of two regimes. We compare this model (denoted the RSMR model) with a single regime mean reverting model (denoted the traditional mean reverting, or TMR, model) which has been used previously in the literature. For parameter calibration, these two models are expressed in the risk-neutral world and the corresponding parameters are calibrated using the prices of traded lumber derivatives, i.e. lumber futures and options on lumber futures. A benefit of calibrating model parameters in this way is that the parameters obtained are risk adjusted so that a forest investment can be valued using the risk-free interest rate.

In the second part of the paper we use the calibrated RSMR and TMR models to solve an optimal harvesting problem. The optimal choice of harvesting date for an even-aged stand of trees and the value of the option to harvest are modeled as a Hamilton-Jacobi-Bellman variational inequality which is solved numerically using a fully implicit finite difference method. The approach is similar to that used in Insley and Lei (2007), except that the model must accommodate the different regimes. We use the same cost and timber yield estimates as in 
Insley and Lei (2007) and hence we are able to compare results. ${ }^{4}$

This paper makes a methodological contribution to the literature. It demonstrates the numerical solution of a dynamic optimization problem in a natural resources context under the assumption of a regime switching stochastic state variable. In the future it is hoped that this methodology may be usefully applied to other types of natural resource investment problems, which are often sufficiently complex that closed-form solutions are unavailable. The paper also makes an empirical contribution in the investigation of the dynamics of lumber prices. To our knowledge the parameterization of risk-adjusted lumber price models using lumber derivatives prices has not been done previously in the literature. Although we are limited by the short maturity dates of traded lumber futures, we find that the regime switching model shows promise as a parsimonious model of timber prices that can be incorporated into problems of forestry investment valuation using standard numerical solutions techniques. In our concluding section we discuss how this and other limitations of the current paper point toward avenues for future research.

The remainder of the paper will be organized as follows. Section 2 presents a brief literature review. Section 3 provides descriptive statistics and preliminary tests on a lumber price time series. Section 4 specifies the lumber price models that will be used in our analysis and details the methodology for calibrating the parameters of these models. Section 5 provides the results of the calibration. Section 6 specifies the forestry investment problem and its numerical solution. Section 7 uses the regime switching and single regime price models to solve for the optimal harvesting time and land value in a tree harvesting problem. Section 8 provides some concluding comments.

\section{Modeling commodity prices: An overview of selected literature}

Stochastic models of commodity prices play a central role for commodity-related risk management and asset valuation. As noted in Schwartz (1997), earlier research into valuing investments contingent on stochastic commodity prices generally adopted an assumption of

\footnotetext{
${ }^{4}$ In Insley and Lei (2007) parameter estimates of the price process were obtained through ordinary least squares on historical lumber price data only.
} 
geometric Brownian motion (GBM), $d P=a P d t+b P d z$, where $P$ denotes commodity prices, $a$ and $b$ are constant, $d z$ is a standard Wiener process. This allowed the procedures developed for valuing financial options to be easily extended to valuing commodity based contingent claims.

Schwartz (1997) and Baker et al. (1998), among others, have emphasized the inadequacy of using GBM to model commodity prices. Under GBM the expected price level grows exponentially without bound. In contrast there is evidence that the real prices of many natural resource-based commodities have shown little upward trend. This is explained by the presence of substitutes as well as improvements in technology to harvest or extract a resource. In addition if a commodity's spot price is assumed to follow GBM, it can be demonstrated using Ito's lemma that the futures price will also follow GBM and both spot and futures prices will have the same constant volatility, (Geman, 2005). However, for most commodities, the volatility of futures prices decreases with maturity, so that the single factor lognormal model such as GBM is not consistent with reality (Pilipovic, 2007, page 233-234). In the literature on optimal tree harvesting, early papers adopting the GBM assumption include Reed and Clarke (1990), Clarke and Reed (1989), Yin and Newman (1995), and Morck et al. (1989).

It is not unreasonable to expect that the workings of supply and demand will result in commodity prices that exhibit some sort of mean reversion. There is also empirical research that supports this claim. For example Bessembinder et al. (1995) find support for meanreversion in commodity prices by comparing the sensitivity of long-maturity futures prices to changes in spot prices.

One possible choice of mean reverting model is a variation of Ornstein-Uhlenbeck process:

$$
d P=\alpha(K-P) d t+\sigma P d z
$$

$\alpha$ is a constant and referred to as the speed of mean reversion. $K$ represents the (constant) long run equilibrium price that $P$ will tend towards. $\sigma$ is a constant and $d z$ is the increment of a Wiener process. In the traditional Ornstein-Uhlenbeck process the variance rate is constant, whereas in Equation (1) the conditional variance of $P$ depends on the level of 
$P$, thereby preventing $P$ from becoming negative. This process is suggested in Dixit and Pindyck (1994) and is adopted in Insley and Rollins (2005) and Insley and Lei (2007) to represent lumber prices in an optimal tree harvesting problem. Other optimal harvesting papers to adopt variations on this mean reverting process include Plantinga (1998) and Gong (1999). Mean reverting processes have also been used in modeling prices for oil, electricity, copper, and other minerals (see Cortazar and Schwartz (1994), Dixit and Pindyck (1994), Pilipovic (2007), Smith and McCardle (1998) and Lucia and Schwartz (2002) for example).

The mean reverting model of Equation (1), while an improvement over GBM, is not entirely satisfactory. It can be shown that under this model the implied volatility of futures prices decreases with maturity, which is a desirable property for modelling commodity prices. However volatility tends to zero for very long maturities, which is not consistent with what is observed in practice. In addition this model presumes a constant long run equilibrium price $(K)$, when in reality $K$ may be better characterized as a stochastic variable. Schwartz and Smith (2000) propose a two-factor model in which the equilibrium price level is assumed to evolve according to GBM and the short-term deviations are expected to revert toward zero following an Ornstein-Uhlenbeck process. In another variation, a commodity's convenience yield is modelled as additional stochastic factor which is assumed to follow a MR process. Schwartz (1997) also develops a three-factor model with stochastic price, convenience yield and interest rate.

Alternative versions of multi-factor models can be derived through variation along a number of dimensions. One possibility is the inclusion of jumps. Saphores et al. (2002) find evidence of jumps in Pacific North West stumpage prices in the U.S. and demonstrate at the stand level that ignoring jumps can lead to significantly suboptimal harvesting decisions for old growth timber.

In devising better models for commodity prices we are faced with a tradeoff between increased realism through the addition of more stochastic factors, jumps, etc., and the added complexity and difficulty of solving for the value of related contingent claims. The optimal tree harvesting problem has the further complication that the asset (a stand of trees) is growing and being harvested over multiple rotations. The timing of harvest and hence the age of the stand depend on price, so that stand age is also stochastic. It is desirable to 
find an approach to modeling timber prices which, while adequately rich, still allows for the solution of the related contingent claim using standard approaches. It is towards this end that we investigate a regime switching model. The regime switching model with two regimes can readily be solved with a finite difference numerical approach.

Jumps in commodity prices are often driven by discrete events such as weather, disease, or economic booms and busts which may persist for months or years. The typical continuous time models with isolated and independent jumps would not capture sustained shifts of this nature where parameters such as volatility and drift differ between regimes. The Markov regime switching $(\mathrm{RS})$ model first proposed by Hamilton (1989) is a promising model for commodity prices. In a RS model, spot prices can jump discontinuously between different states governed by state probabilities and model parameters. The RS model can be used to capture the shifts between "abnormal" and "normal" equilibrium states of supply and demand for a commodity.

Versions of the RS model have previously been applied to the investigation of business cycle asymmetry in Hamilton (1989) and Lam (1990), heteroscedasticity in time series of asset prices in Schwert (1996), the effects of oil prices on U.S. GDP growth in Raymond and Rich (1997). RS specifications for modeling stochastic commodity prices are studied in Deng (2000) and de Jong (2005) for electricity prices and in Chen and Forsyth (2008) for natural gas prices. Deng (2000) shows that by incorporating jumps and regime switching in modeling electricity prices, as opposed to the commonly used GBM model, the values of short-maturity out-of-the-money options approximate market prices very well. de Jong (2005) indicates that RS models are better able to capture the market dynamics than a GARCH(1,1) or Poisson jump model. Chen and Forsyth (2008) show that the RS model outperforms traditional one-factor MR model by solving the gas storage pricing problem using numerical techniques.

In this paper, we examine the application of a RS model to lumber prices to investigate whether it represents an improvement over a single regime model that has been used previously in the forestry literature. We will use the prices of lumber derivatives to calibrate the parameters of the price process in each of two regimes, and compare with the results of a calibration with a single regime only. Allowing for two regimes may be thought of 
as a generalization of the more restrictive one regime case, with the regimes representing two distinct sets of parameter values, perhaps reflecting good and bad times, in which the volatility, long run equilibrium price level and speed of mean reversion are all able to change. The assumption of two regimes is acknowledged as a limitation, as it may be that the use of three or more regimes is more appropriate. The possible inclusion of more than two regimes is left for future research. It must also be acknowledged that independent jumps such as described in Merton (1976) may occur within each regime. This possibility is also left for future research. It is hoped that the two regime model in this paper is rich enough description of timber prices so that the addition of other stochastic factors, more regimes and jumps is unnecessary.

\section{A first look at lumber markets and prices}

Forest products, including logs, lumber, and paper, are traded worldwide and Canada is a major player in this market, accounting for $14 \%$ of the value of world forest product exports in 2006. ${ }^{5}$ Canada's forest product exports are mainly destined for the United States (over $75 \%$ went to the U.S. in 2006) and Canada is the source of over $80 \%$ of U.S. lumber imports. ${ }^{6}$

Forest product prices in North America are affected by swings in housing starts and other demand sources, supply factors such as fire and pests that plague forests from time to time, regulatory changes and by the increased integration of forest product markets worldwide. In addition, forest operations in Canada have been severely affected by on-going trade disputes between Canada and the U.S.. Forest product prices are almost all quoted in U.S. dollars, which is an added source of volatility for Canadian forest product producers who receive revenue in U.S. dollars but pay silviculture and harvesting costs in Canadian dollars. Participants in forest product markets can hedge some risks by buying or selling futures contracts. Lumber futures contracts with expiry dates for up to one year in the future have been traded on the Chicago Mercantile Exchange (CME) since 1969.

\footnotetext{
${ }^{5}$ Source: FAOstat database, Food and Agricultural Organization of the United Nations, http://faostat.fao.org/site/381/DesktopDefault.aspx?PageID=381

${ }^{6}$ Source: Random Lengths, "Yardstick" and Canada's Forests, Statistical Data, Natural Resources Canada, http://canadaforests.nrcan.gc.ca/statsprofileCanada (retrieved May 4, 2008).
} 


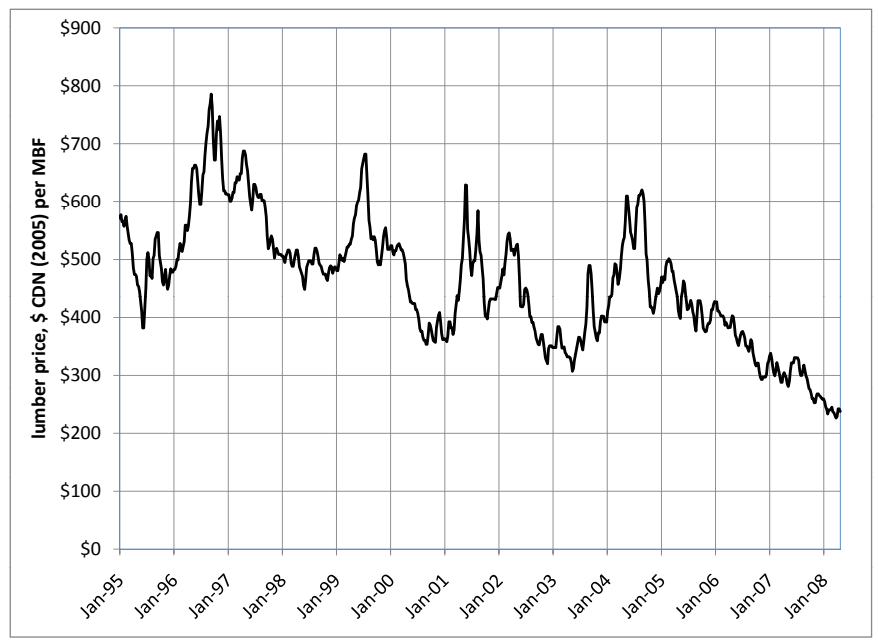

Figure 1: Real prices of softwood lumber, Toronto, Ontario. Weekly data from January 6th, 1995 to April 25th, 2008, \$Cdn./MBF, (MBF $\equiv$ thousand board feet). Nominal prices deflated by the Canadian Consumer Price Index, base year $=2005$.

Real weekly spot prices for Canadian lumber are shown in Figure 1. Periods of boom and bust are evident in the diagram, with the especially difficult time in the industry clearly apparent from mid-2004 onward. This reflects declining lumber prices in the United States as well as the appreciation of the Canadian dollar which rose from $0.772 \$$ U.S. $\$ \mathrm{Cdn}$ in January 2004 to 0.998 \$U.S. $\$$ Cdn in January 2008. Descriptive statistics for the lumber price time series and its corresponding return are provided in Table 1. Return is calculated as $\ln \left(P_{t} / P_{t-1}\right)$ where $P_{t}$ refers to price at time $t$. Weekly data are used, however, the minimum, maximum, and mean returns as well as the standard deviation have been annualized. The returns of the price time series exhibit excess kurtosis, which implies that a pure GBM model is not able to fully describe the dynamics of lumber price process. ${ }^{7}$ A formal test of normality (the Jarque-Bera test) strongly rejects the null hypothesis that return follows a normal distribution.

\footnotetext{
${ }^{7}$ A GBM model implies that price follows a log normal distribution or the log returns are normal. For a normal distribution skewness is zero and kurtosis is three.
} 


\begin{tabular}{c|cccccc}
\hline \hline Item & Max & Min & Mean & Std. Dev. & Skewness & Kurtosis \\
\hline \hline Cdn(2003) $\$ / m^{3}$ & 785.6 & 226.5 & 459.3 & 109.6 & 0.2151 & 2.711 \\
Weekly Return (annualized) & $653.0 \%$ & $-644.5 \%$ & $-6.5 \%$ & $21.5 \%$ & 0.134 & 4.448 \\
\hline
\end{tabular}

TABLE 1: Descriptive statistics for the lumber price time series (as shown in Figure 1) and its returns, from January 6th, 1995 to April 25th, 2008. The return is the continuously compounded return.

\section{Calibration of Lumber Spot Price Models}

In this section we specify and parameterize the two timber price models that will be used in our optimal harvesting problem. The models we consider are a traditional mean reverting process (TMR) as used in Insley and Rollins (2005) and Insley and Lei (2007) and a regime switching model (the RSMR model) in which the spot price follows potentially two different mean reverting processes. We calibrate the two models using lumber derivatives prices and present evidence as to which can better describe timber prices.

\subsection{RSMR and TMR models}

The RSMR model for lumber price, $P$, is given by the following stochastic differential equation $(\mathrm{SDE})$ :

$$
d P=\alpha\left(s_{t}\right)\left(K\left(s_{t}\right)-P\right) d t+\sigma\left(s_{t}\right) P d Z
$$

where $s_{t}$ is a two-state continuous time Markov chain, taking two values 0 or 1 . The value of $s_{t}$ indicates the regime in which the lumber price resides at time $t$. Define a Poisson process $q^{s_{t} \rightarrow 1-s_{t}}$ with intensity $\lambda^{s_{t} \rightarrow 1-s_{t}}$. Then

$$
\begin{aligned}
d q^{s_{t} \rightarrow 1-s_{t}} & =1 \quad \text { with probability } \lambda^{s_{t} \rightarrow 1-s_{t}} d t \\
& =0 \quad \text { with probability } 1-\lambda^{s_{t} \rightarrow 1-s_{t}} d t
\end{aligned}
$$

In other words, the probability of regime shifts from $s_{t}$ to $1-s_{t}$ during the small time interval $d t$ is $\lambda^{s_{t} \rightarrow 1-s_{t}} d t$. The probability of the lumber price staying in the current regime $s_{t}$ is $1-\lambda^{s_{t} \rightarrow 1-s_{t}} d t$.

In this RSMR model, each parameter in the equation is allowed to shift between two 
states implied by $s_{t} . K\left(s_{t}\right)$ is the long-run equilibrium level to which the price tends toward following any disturbance. We refer to $\alpha\left(s_{t}\right)$ as the mean reversion rate; the higher its value the more quickly price reverts to its long run mean value. $\sigma\left(s_{t}\right)$ denotes price volatility; $d Z$ is the increment of the standard Wiener process. The stochastic factors for the two regimes are perfectly correlated. Therefore there is a common $d Z$ for two different SDE.

The TMR model, which is calibrated for comparison with the RSMR model, is described by the following stochastic differential equation:

$$
d P=\alpha(K-P) d t+\sigma P d Z
$$

In contrast with RSMR model, the parameters in the above equation are constant, instead of being regime dependent,

Ideally we would rely on statistical tests to determine which of Equation (2) or Equation (3) is a better model of lumber prices. However, since the parameter $\lambda^{s_{t} \rightarrow 1-s_{t}} d t$ is defined only in relation to $s_{t}$ in Equation (2) and is not present in (3), the traditional asymptotic tests such as the likelihood ratio, Lagrange multiplier and Wald tests do not have a standard asymptotic distribution and cannot be used (Davies, 1977, 1987). As is detailed later in this section, we rely on the calibration procedure to determine which model best describes lumber prices.

For the regime switching model, Hamilton (1989) presents a nonlinear filter and smoother to get statistical estimates of the unobserved state, $s_{t}$, given observations on values of $P_{t}$. The marginal likelihood function of the observed variable is a byproduct of the recursive filter, allowing parameter estimation by maximizing this likelihood function. The parameters estimated in this way are under the P-measure implying that a corresponding market price of risk has to be estimated as well.

In contrast to Hamilton's method, in Chen and Forsyth (2008) the parameters of the risk-adjusted processes are calibrated by using natural gas derivative contracts, meaning that the parameters thus estimated are under the risk neutral probability measure, Q-measure, allowing the assumption of risk neutrality in the subsequent contingent investment valuation. In this paper, we follow a similar procedure to Chen and Forsyth (2008) using lumber 
derivatives, and present the details here for the convenience of the reader. For all parameter values except the volatilities, lumber futures contracts are used in the calibration process. For reasons explained below, options on lumber futures are used to calibrate volatilities.

\subsection{Calibration using futures prices}

Ito's lemma is used to derive the partial differential equations characterizing lumber futures prices for the two price models. These partial differential equations are simplified to a system of ordinary differential equations which can be solved numerically to give futures prices consistent with different parameter values. The calibration procedure determines those parameter values (except for the volatilities) which produce calculated futures prices that most closely match a time series of market futures prices.

Beginning with the TMR model, let $F(P, t, T)$ denote the futures price at time $t$ with maturity T. A futures contract is a contingent claim. From Ito's lemma, the PDE describing the futures price is given by Equation (4).

$$
F_{t}+\alpha(K-P) F_{P}+\frac{1}{2} \sigma^{2} P^{2} F_{P P}=0
$$

At the expiry date $T$ the futures price will equal the spot price, which gives the boundary condition: $F(P, T, T)=P$

The solution of this PDE is known to have the form

$$
F(P, t, T)=a(t, T)+b(t, T) P
$$

Substituting Equation (5) into Equation (4), gives the following ODE system

$$
\begin{aligned}
a_{t}+\alpha K b & =0 \\
b_{t}-\alpha b & =0
\end{aligned}
$$

where $a_{t} \equiv \partial a / \partial t$ and $b_{t} \equiv \partial b / \partial t$. The boundary conditions: $a(T, T)=0 ; b(T, T)=1$ are required in order for $F(P, T, T)=P$ to hold. 
Next for the RSMR model, let $F\left(s_{t}, P, t, T\right)$ denote the lumber futures price at time $t$ with maturity $T$ in regime $s_{t}$, where $s_{t} \in\{0,1\}$. The no-arbitrage value $F\left(s_{t}, P, t, T\right)$ can be expressed as the risk neutral expectation of the spot price at $T$.

$$
F\left(s_{t}, P, t, T\right)=E^{Q}\left[P(T) \mid P(t)=p, s_{t}\right]
$$

The lumber futures price is a derivative contract whose value depends on the stochastic price and the corresponding regime. Using Ito's lemma for a jump process the conditional expectation satisfies two PDEs, one for each regime, given by: ${ }^{8}$

$$
F\left(s_{t}\right)_{t}+\alpha\left(s_{t}\right)\left(K\left(s_{t}\right)-P\right) F\left(s_{t}\right)_{P}+\frac{1}{2} \sigma\left(s_{t}\right)^{2} P^{2} F\left(s_{t}\right)_{P P}+\lambda^{s_{t} \rightarrow\left(1-s_{t}\right)}\left(F\left(1-s_{t}\right)-F\left(s_{t}\right)\right)=0
$$

with the boundary condition: $F\left(s_{t}, P, T, T\right)=P$.

The solution to these PDEs is known to have the form

$$
F\left(s_{t}, P, t, T\right)=a\left(s_{t}, t, T\right)+b\left(s_{t}, t, T\right) P
$$

Substituting Equation (9) into Equation (8) yields the following ordinary differential equation (ODE) system, ${ }^{9}$

$$
\begin{gathered}
a\left(s_{t}\right)_{t}+\lambda^{s_{t} \rightarrow\left(1-s_{t}\right)}\left(a\left(1-s_{t}\right)-a\left(s_{t}\right)\right)+\alpha\left(s_{t}\right) K\left(s_{t}\right) b\left(s_{t}\right)=0 \\
b\left(s_{t}\right)_{t}-\left(\alpha\left(s_{t}\right)+\lambda^{s_{t} \rightarrow\left(1-s_{t}\right)}\right) b\left(s_{t}\right)+\lambda^{s_{t} \rightarrow\left(1-s_{t}\right)} b\left(1-s_{t}\right)=0
\end{gathered}
$$

with boundary conditions $a\left(s_{t}, T, T\right)=0 ; b\left(s_{t}, T, T\right)=1 . a\left(s_{t}\right)_{t} \equiv \partial a(s, t) / \partial t$ and $b\left(s_{t}\right)_{t} \equiv$ $\partial b(s, t) / \partial t$

Note that the volatility, $\sigma$, does not appear in Equations (9) and (10). This implies that the futures price at time $t, F\left(s_{t}, P, t, T\right)$, does not depend on spot price volatilities in either regime, $\sigma^{0}$ and $\sigma^{1}$. Hence we cannot use lumber futures prices to calibrate the spot price volatility. As in Chen and Forsyth (2008), lumber futures option prices are used to calibrate

\footnotetext{
${ }^{8} F\left(s_{t}\right) \equiv F\left(s_{t}, P, t, T\right)$

${ }^{9} a\left(s_{t}\right) \equiv a\left(s_{t}, t, T\right)$ and $b\left(s_{t}\right) \equiv b\left(s_{t}, t, T\right)$.
} 
the volatility. The same follows for the single regime case where we observe that $\sigma$ is absent from Equations (5) and (6).

A least squares approach is used for calibrating the risk-neutral parameter values. Let $\theta$ denote the set of parameters calibrated to the futures price data, where $\theta_{R S M R}=\left\{\alpha\left(s_{t}\right), K\left(s_{t}\right)\right.$, $\left.\lambda^{s_{t} \rightarrow\left(1-s_{t}\right)} \mid s_{t} \in\{0,1\}\right\}$ and $\theta_{T M R}=\{\alpha, K\}$. In particular, at each observation day $t$, where $t \in\left\{1, \ldots, t^{*}\right\}$, there are $T^{*}$ futures contracts with $T^{*}$ different maturity dates. For the RSMR model the calibration is performed by solving the following optimization problems:

$$
\min _{\theta_{R S M R}} \sum_{t} \sum_{T}\left(\hat{F}\left(\hat{s}_{t}(\theta), P(t), t, T ; \theta\right)-F(t, T)\right)^{2}
$$

where $F(t, T)$ is the market futures price on the observation day $t$ with maturity $T$. $\hat{F}\left(\hat{s}_{t}(\theta)\right.$, $P(t), t, T ; \theta)$ is the corresponding model implied futures price computed numerically determined in Equations (9) and (10) using the market spot price $P(t)$ and the parameter set $\theta$ in regime $\hat{s}_{t}(\theta)$, where

$$
\hat{s}_{t}(\theta)=\underset{s_{t} \in\{0,1\}}{\operatorname{argmin}} \sum_{T}\left(\hat{F}\left(s_{t}, P(t), t, T ; \theta\right)-F(t, T)\right)^{2}
$$

At each $t$, the regime $\hat{s}_{t}(\theta)$ will be determined by minimizing the sum of squared errors between the market futures prices $F$, and the corresponding model implied futures prices $\hat{F}$, for all $T^{*}$ at $t$ for a given $\theta$. The calibrated parameter set $\theta$ will then minimize the distance between $F$ and $\hat{F}$ for all $t^{*}$. The regime where price resides at any particular date is determined via the calibration.

Similarly, for TMR model, the optimization problem becomes

$$
\min _{\theta_{T M R}} \sum_{t} \sum_{T}(\hat{F}(P(t), t, T ; \theta)-F(t, T))^{2}
$$

where $\hat{F}(P(t), t, T ; \theta)$ is the model implied futures price. 


\subsection{Calibration of volatilities using options on futures}

In this section, the spot price volatilities are calibrated for the two different price models using market European call options on lumber futures. For the RSMR model, let $\bar{V}\left(s_{t}, F, t, T_{v}\right)$ denote the (theoretical) European call option value on the underlying lumber futures contract $F$ at time $t$ with maturity at $T_{v}$ in regime $s_{t} . F\left(s_{t}, t, T\right)$ represents the price of the underlying futures contract at time $t$ with maturity at $T$, where $T \geq T_{v}$. Let $X$ be the strike price of option. In the risk-neutral world, $\bar{V}\left(s_{t}, F, t, T_{v}\right)$ can be expressed as

$$
\bar{V}\left(s_{t}, F, t, T_{v}\right)=e^{-r\left(T_{v}-t\right)} E^{Q}\left[\max \left(F\left(s_{T_{v}}, T_{v}, T\right)-X, 0\right) \mid F\left(s_{t}, t, T\right)=F, s_{t}\right]
$$

For our calibration we must assume that $T=T_{v}$ which implies that $\bar{V}\left(s_{t}, F, t, T_{v}\right)=$ $\bar{V}\left(s_{t}, F, t, T\right)$ and $F\left(s_{T_{v}}, T_{v}, T\right)=F\left(s_{T}, T, T\right) .{ }^{10}$ Therefore Equation (14) can be transformed to

$$
\begin{array}{r}
\bar{V}\left(s_{t}, F, t, T\right)=e^{-r(T-t)} E^{Q}\left[\max \left(F\left(s_{T}, T, T\right)-X, 0\right) \mid F\left(s_{t}, t, T\right)=F, s_{t}\right] \\
\quad=e^{-r(T-t)} E^{Q}\left[\max (P(T)-X, 0) \mid a\left(s_{t}, t, T\right)+b\left(s_{t}, t, T\right) P(t)=F, s_{t}\right]
\end{array}
$$

where $P(T)$ is the lumber spot price. The second equality uses the fact that $F\left(s_{T}, T, T\right)=$ $P(T)$ at the maturity date $T$, and Equation (9) which gives the relation between the spot and futures price.

For calibration purposes, the value of a European call option on the spot price, $P$, is needed. In reality options on lumber futures exist, but not options on spot lumber. We therefore create a hypothetical European call option and derive its relationship to options on lumber futures. Let $V\left(s_{t}, P, t, T\right)$ denote the value of a hypothetical call option on spot lumber at time $t$ with maturity $T$ in regime $s_{t}$. This value of this option can be expressed

\footnotetext{
${ }^{10}$ In reality $T>T_{v}$. On the Chicago Mercantile Exchange, futures contracts on lumber expire on approximately the 15th of the month, whereas options on a futures contract expire on the last business day of the month prior to the expiration of the futures contract. In our empirical work we justify this assumption by retrieving options prices some months before their expiry, so that the impact of the difference between $T$ and $T_{v}$ will be small.
} 
in the form of the risk-neutral expectation

$$
V\left(s_{t}, P, t, T\right)=e^{-r(T-t)} E^{Q}\left[\max (P(T)-X, 0) \mid P(t)=P, s_{t}\right]
$$

Given that lumber price $P$ follows RSMR, the option value $V\left(s_{t}, P, t, T\right)$ satisfies the coupled PDEs

$$
\begin{array}{r}
V\left(s_{t}\right)_{t}+\alpha\left(s_{t}\right)\left(K\left(s_{t}\right)-P\right) V\left(s_{t}\right)_{P}+\frac{1}{2} \sigma\left(s_{t}\right)^{2} P^{2} V\left(s_{t}\right)_{P P}-r V\left(s_{t}\right)+ \\
\lambda^{s_{t} \rightarrow 1-s_{t}}\left[V\left(1-s_{t}\right)-V\left(s_{t}\right)\right]=0, \quad s_{t} \in\{0,1\}
\end{array}
$$

with the boundary condition: $V\left(s_{t}, P, T, T\right)=\max [P(T)-X, 0]$. The price of this hypothetical option $V\left(s_{t}, P, t, T\right)$ can be found by numerically solving the coupled PDEs in Equation (17) using a fully implicit finite difference scheme.

Comparing equations (15) and (16), the following relationship holds.

$$
\bar{V}\left(s_{t}, F, t, T\right)=V\left(s_{t}, \frac{F-a\left(s_{t}, t, T\right)}{b\left(s_{t}, t, T\right)}, t, T\right)
$$

Therefore, after finding $V\left(s_{t}, P, t, T\right)$ by solving the Equation (17), the theoretical lumber option value $\bar{V}\left(s_{t}, F, t, T\right)$ can be found from Equation (18) using interpolation.

For the calibration of volatility, we use a least squares approach to minimize the difference between the theoretical value of options on lumber futures with their market value. In particular for the RSMR model, we solve the following optimization problem:

$$
\min _{\sigma^{0}, \sigma^{1}} \sum_{K}\left(\bar{V}\left(\hat{s}_{t}, F\left(t, T_{1}\right), t, T_{1} ; \theta, K, \sigma^{0}, \sigma^{1}\right)-V\left(t, T_{1} ; K\right)\right)^{2}
$$

where $\bar{V}\left(\hat{s}_{t}, F, t, T_{1} ; \theta, K, \sigma^{0}, \sigma^{1}\right)$ represents the corresponding model implied (or theoretical) option value at time $t$ with maturity $T$ and strike price $K$ and $V\left(t, T_{1} ; K\right)$ is the market value of lumber call options on futures. $T^{*}$ option contracts with $T^{*}$ different strike prices are needed for volatility calibration. The calibrated parameter set $\{\sigma(0), \sigma(1)\}$ will minimize the square distance between $\bar{V}$ and $V$.

Similarly, for the TMR model, let $\bar{V}(F, t, T)$ and $V(P, t, T)$ represent the theoretical 
value of European call option on lumber futures and the value of a hypothetical European call option on lumber respectively. ${ }^{11}$ The corresponding PDE for characterizing $V(P, t, T)$ is expressed as

$$
V_{t}+\alpha(K-P) V_{P}+\frac{1}{2} \sigma^{2} P^{2} V_{P P}-r V=0
$$

with boundary condition: $V(P, T, T)=\max [P(T)-X, 0]$. Given the relationship ${ }^{12}$

$$
\bar{V}(F, t, T)=V\left(\frac{F-a(t, T)}{b(t, T)}, t, T\right)
$$

the model implied (theoretical) option value $\bar{V}(F, t, T)$ can be computed after getting $V(P, t, T)$ by solving the above PDE.

Similarly, for the TMR model, the optimization problem becomes:

$$
\min _{\sigma} \sum_{K}\left(\bar{V}\left(F\left(t, T_{1}\right), t, T_{1} ; \theta, K, \sigma\right)-V\left(t, T_{1} ; K\right)\right)^{2}
$$

where $V\left(t, T_{1} ; K\right)$ is the market value of lumber call options on futures.

\section{Calibration results and model comparison}

\subsection{Data description: lumber futures and options on futures}

Lumber market futures and options on futures are used to calculate the risk neutral spot price process. Four different futures contracts corresponding to each observation date for every Friday from January 6th, 1995 to April 25th, 2008 will be employed in the calibration. The average maturity days for these four futures contracts which trade on the Chicago Mercantile Exchange (CME), are about 30, 90, 150 and 210. Since we are interested in estimating the stochastic process for real lumber prices for a Canadian forestry problem, future prices were deflated by the consumer price index and converted to Canadian dollars. ${ }^{13}$

\footnotetext{
${ }^{11}$ We assume $T_{v} \approx T$ in this model as well.

${ }^{12}$ This relationship is derived in the same way as equation (18).

${ }^{13}$ For CME Random Length Lumber futures, the delivery contract months are as follows: January, March, May, July, September and November. There are six lumber futures on each day only the first four of which are actively traded. Therefore, only the first four futures contracts are used in parameter calibration. The
} 
The call options on futures used to calibrate volatilities are also from the CME. Two sets of six call options written on the same futures contract were chosen. The call options expire on October 31st, 2008 while the underlying futures contract expires on November 14, 2008. (At the CME, the lumber options expire the last business day in the month prior to the delivery month of the underlying futures contract.) The first set of six options was obtained on May 23rd, 2008 and the price of the corresponding futures contract was $260.8 \$$ U.S./mbf. The second set was obtained on May 30th, 2008 and the futures price on that day was 260.9 \$U.S./mbf. The strike prices of the six call options range from 260 to 310 \$U.S./mbf.

In our case since the underlying futures contracts expires on November 14, 2008 and the options expire on October 31, 2008, $T_{v}<T$. For the calibration, we must assume that $T_{v}=T$ holds approximately. To justify this assumption, we appeal to the fact that options prices were retrieved in May 2008, some months before their expiry.

\subsection{Calibration Results}

Tables 2 and 3 present the calibration results for parameter values under the risk neutral measure in the RSMR model. We observe two quite different regimes in the Q-measure. Regime 1 has a much higher equilibrium price level, $K(1)$, but a lower speed of mean reversion, $\alpha(1)$, compared to regime 0 . The risk neutral probability of switching out of regime 1 is much lower than the risk neutral probability of switching out of regime 0 . The steady state probability that price (in the risk neutral world) will be found in regime 1 is calculated to be $98 \%{ }^{14}$ Calibrated volatility in regime 0 is very low at $0.38 \%$ compared to $25.5 \%$ in regime 1 (see Table 3).

These parameter estimates for the RSMR model describe a situation where price is mostly in regime 1 with the high long run equilibrium price and a moderate pace of mean reversion. Ignoring volatility and the risk of regime change, the mean reversion speed $\alpha(1)=0.04$ implies the half-life for returning to the long run equilibrium is 1.7 years. ${ }^{15}$ Occasionally price reverts to regime 0 which has a significantly lower equilibrium price and very little

last day of trading is the business day prior to the 16th calendar day of the contract month.

${ }^{14}$ This is calculated as $\lambda^{0 \rightarrow 1} /\left(\lambda^{0 \rightarrow 1}+\lambda^{1 \rightarrow 0}\right)=98 \%$. See Grimmett and Stirzaker (2001, pages 256-259).

${ }^{15}$ Solving the differential equation $d P=\alpha(K-P) d t$, the time to reduce $\left(P_{t}-K\right)$ by half is $-\ln (0.5) / \alpha$. 


\begin{tabular}{cccccc}
\multicolumn{6}{c}{ RSMR Model } \\
\hline \hline$\alpha(0)$ & $\alpha(1)$ & $K(0)$ & $K(1)$ & $\lambda^{0 \rightarrow 1}$ & $\lambda^{1 \rightarrow 0}$ \\
3.61 & 0.40 & 71.92 & 516.64 & 17.09 & 0.39 \\
\hline \multicolumn{5}{c}{ TMR Model } \\
\hline \hline \multicolumn{5}{c}{$\alpha$} & $K$ \\
& 0.69 & 341.00 & \\
\hline
\end{tabular}

TABLE 2: Calibrated parameter values for the RSMR and TMR model, $K(0), K(1)$ and $K$ are in $\$ C d n(2005) /$ cubic metre.

\begin{tabular}{cc|c}
\hline \hline \multicolumn{2}{c|}{ RSMR Model } & TMR Model \\
\hline \hline$\sigma(0)$ & $\sigma(1)$ & $\sigma$ \\
0.0038 & 0.2545 & 0.28 \\
\hline
\end{tabular}

TABLE 3: Calibrated volatilities for the RSMR and TMR models

volatility. Regime 0 may be thought of as a depressed state, and in the risk neutral world this state is not expected to persist for long. The mean reversion rate is much higher in regime 0 than in regime 1.

Calibrated parameter values for the TMR model are also reported in Tables 2 and 3. The long-run price level, $K$, and mean reversion rate $\alpha$ in the TMR model fall between regime 1 and regime 0 values in the RSMR model while volatility is close to that of regime 1.

It is tempting to interpret these parameter estimates in terms of the behaviour of historical lumber prices, but this would be invalid since these are risk adjusted or Q-measure estimates. If we assume that in the real world, or under the P-measure, the spot price follows a process like Equation (2), then we can derive the relationship between P-measure and Q-measure parameters. We show in Appendix A that given assumptions about the signs of the speed of mean reversion, $\alpha\left(s_{t}\right)$, and the market price of risk for lumber price diffusion, denoted $\beta_{P}$, then the speed of mean reversion in the risk neutral world will exceed that of the real world. In addition, the long run equilibrium price $K\left(s_{t}\right)$ will be lower in the risk neutral world than the real world. It makes intuitive sense that the risk adjustment in moving to the Q-measure results in a price process which reverts at a faster rate to a lower long run equilibrium level. This would make the Q-measure process more pessimistic, as expected. It is also shown in Appendix A that volatility is the same in the real and risk-neutral worlds. 


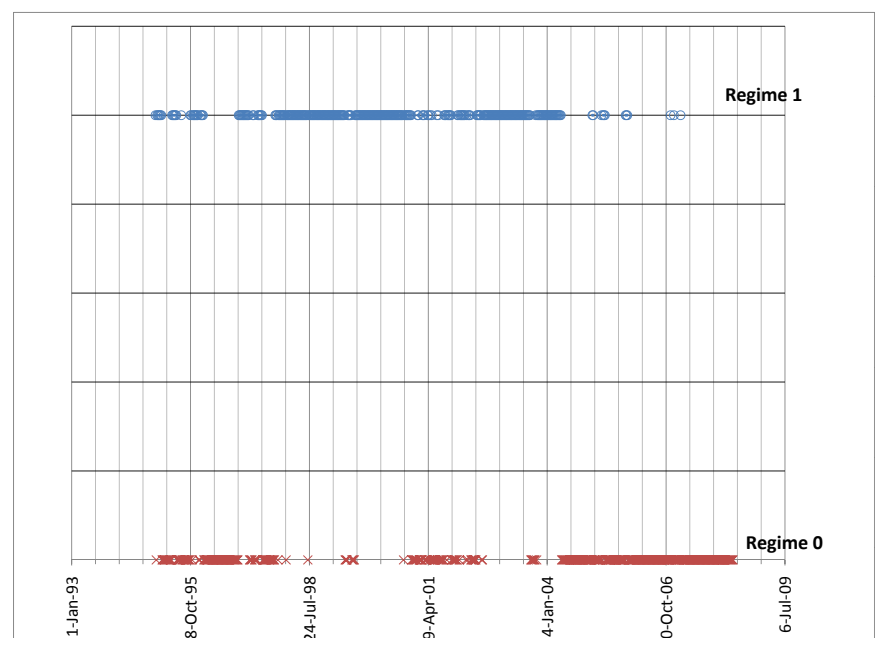

FIGURE 2: Implied regimes in the period under consideration by RSMR model. Blue O's on upper line indicate time steps in regime 1 and reddish $X$ 's on lower line indicate time steps in regime 0.

Further, the risk neutral intensity of switching regimes, $\lambda^{s_{t} \rightarrow\left(1-s_{t}\right)}$, equals the market price of risk for regime switching, which we denote $\beta_{s w}$. Hence the calibrated risk adjusted probability $\lambda^{s_{t} \rightarrow\left(1-s_{t}\right)} d t$ may be quite different from the P-measure probability of switching regimes. It is also shown in Appendix A that if we assume a small positive market price of stochastic price risk, $\beta_{P}$, then for the parameter values in this example the high price regime in the risk neutral world (regime 1) is also the high price regime in the real world.

Our calibration results allow us to determine the regime that price most likely resides in for any given date. To do this we compare the calibration error in both regimes, and assume that price resides in the regime where the calibration error is lowest. From this we can derive an estimate of the physical probability of being in either regime, which may be contrasted with the risk neutral probabilities. Regimes in the period under consideration (1995 to 2008) as implied by the RSMR model are plotted in Figure 2.

We observe in Figure 2 that price fluctuates between the two regimes and there are distinct intervals when price appears to remain in one regime or the other. It is interesting to consider whether these regime shifts coincide with any particular events or shocks in lumber markets. For example, from the middle of the year 1998 to the beginning of year 
2001, lumber prices mainly stay in high mean regime (regime 1). This period followed the signing of the five-year trade agreement between the United States and Canada in 1996. Under this Softwood Lumber Agreement, Canadian lumber exports to the United States were limited to a specified level that would be duty free. We hypothesize that this quantity restriction would support lumber prices to remain in the high price regime. The trade agreement expired in April 2001 and the two countries were unable to reach consensus on a replacement agreement. From Figure 2 we observe that during the period between middle 2001 to late 2002, lumber prices fluctuate between the two regimes. Even though, a new agreement between Canada and the United States was implemented in 2006, this deal was criticized as "one-sided" and a "bad deal for Canada". After the middle of 2004 until 2008, lumber prices stay in the low mean regime most of time. The lumber industry has been severely affected by the global financial crisis that began in 2007 and precipitated a drastic fall in the number of new housing starts. The linking of the probability of being in either of the regimes to current events in lumber markets is just a rough intuitive analysis. However, the shifting that we observe between the two regimes lends support for a regime shifting model to account for the different circumstances faced by the industry in good times and bad times.

From the data used in Figure 2 we can estimate that over the 1995 to 2008 period, price is 51.4 percent of the time in regime 0 and 48.6 percent of the time in regime 1 . This contrasts with the risk neutral probabilities noted above which imply that in the risk neutral world price remains in the high price regime $98 \%$ of the time. It is surprising that the risk adjusted probability of staying in the high price regime is larger than the actual probability, which seems to imply a more optimistic view in the Q-measure. However the impact of moving to the risk neutral world is reflected in adjustments to all of the parameters, so we cannot say a priori what the directions of individual adjustments will be. We noted above that the speed of mean reversion is higher and the equilibrium price level is lower, which present a more pessimistic view of price. 


\begin{tabular}{c|ccccc}
\hline \hline \multicolumn{7}{c}{ Mean absolute error } \\
\hline \hline$T$ & 30 & 90 & 150 & 210 & Overall \\
\hline \multicolumn{7}{c}{ RSMR model } \\
\hline In dollars & 22.23 & 18.50 & 18.97 & 20.56 & 20.07 \\
In percentage & 5.65 & 4.49 & 4.56 & 5.00 & 4.93 \\
\hline \multicolumn{7}{c}{ TMR model } \\
In dollars & 39.33 & 30.90 & 30.49 & 34.48 & 33.80 \\
In percentage & 10.36 & 7.85 & 7.48 & 8.21 & 8.47 \\
\hline
\end{tabular}

TABLE 4: Mean absolute errors for all the four different futures contracts in both RSMR and TMR models, expressed in dollars and in percentage. $T$ refers to the number of days to maturity

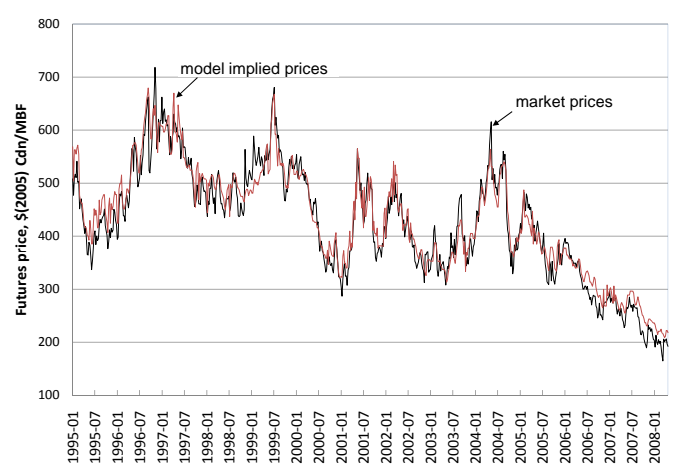

(A) f1: futures contracts with average 30 days to maturity.

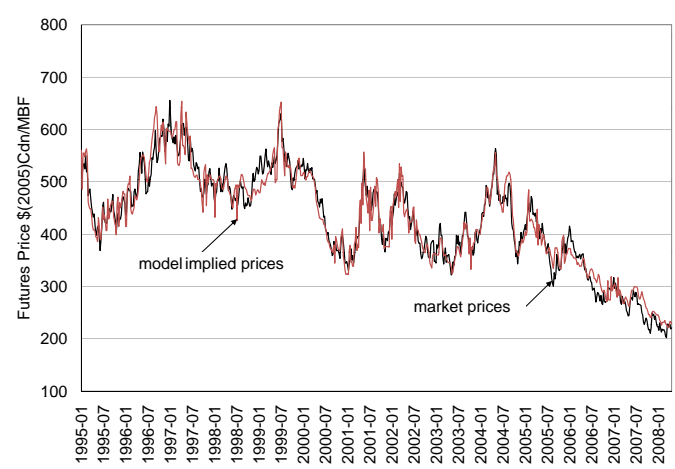

(B) f2: futures contract with average 90 days to maturity.

FIGURE 3: RSMR model implied futures prices and market futures prices for two futures contracts. $f 1$ has the largest error while f2 has the smallest error in Table 4.

\subsection{Model comparison}

Table 4 reports the mean absolute errors for the four futures contracts used to calibrate the RSMR and the TMR models. From the last column, it appears that the RSMR model outperforms the TMR model, since the overall average errors expressed in two different ways are lower in the RSMR model. The RSMR model also has lower errors for each of the four futures contracts individually. Figures 3 and 4 show plots of the model implied futures prices and market futures prices for the two futures contracts corresponding to the largest and smallest calibration errors from Table 4. The closer fit of the RSMR model to market data is noticeable through visual inspection of these graphs. 


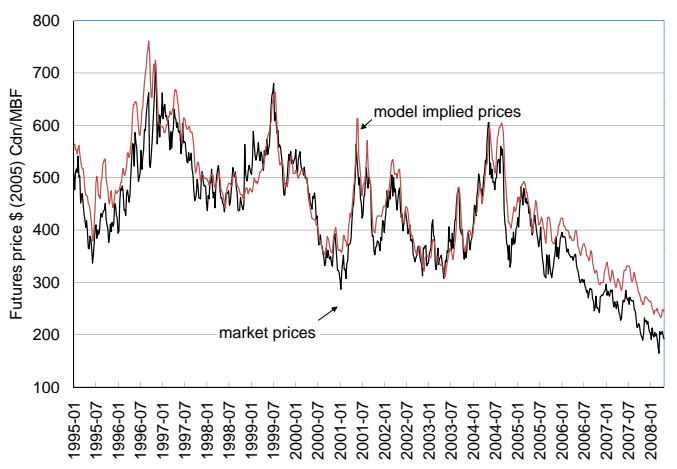

(A) f1: futures contracts with average 30 days to maturity.

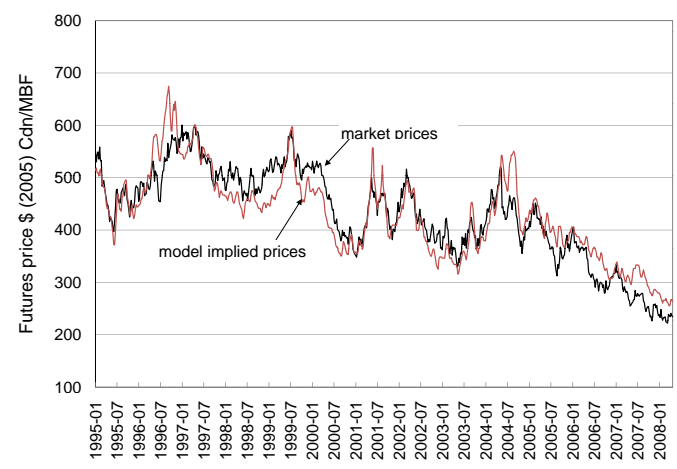

(B) f3: futures contracts with average 90 days to maturity.

FigURE 4: TMR model implied futures prices and market futures prices for two futures contracts, $f 1$ has the largest error while f3 has the smallest error from Table 4.

\section{Specification of the optimal harvesting problem and its numerical solution}

After analyzing the dynamics of the lumber price process and calibrating all the parameter values of the corresponding model, we are ready to solve for the value of a forestry investment. We will value a hypothetical stand of trees in Ontario's boreal forest using both price models examined in this paper. We will investigate whether use of these models in a realistic optimal harvesting problem will result in different land values and optimal harvesting ages. We use the same investment problem as in Insley and Lei (2007). In Insley and Lei (2007) a TMR process was used and the estimation procedure was carried out through ordinary least squares on spot price data. We compare the regime switching model with the result of the single-factor mean reversion process and also the results from Insley and Lei (2007).

In the following sections, a real options model of the forestry investment valuation will be developed assuming lumber prices follow the RSMR process. Coupled partial differential equations (PDEs) characterizing the values of the option to harvest the trees will be derived

using contingent claim analysis. A finite difference method will be employed to solve the PDEs numerically given appropriate boundary conditions. The model and numerical solution scheme for the TMR price case is described in Insley and Rollins (2005). 
In deriving these PDEs it is assumed that there exist financial assets which depend on the price of lumber and can be used to hedge away the price diffusion risk and the risk of a regime switch. It is shown in Kennedy (2007) that "[f] or an N-state regime- switching model in which the underlying is tradeable, the introduction of an additional $N-1$ instruments will complete the market. The instantaneous diffusion and regime-switching risk of an option position can be eliminated using these instruments, such that perfect hedging is possible when rebalancing is done continuously." (See also Naik (1993).) This contrasts with the jump-diffusion model with random jump size when perfect hedging is impossible as it would require an infinite number of hedging instruments. However even in this case it has been found that an acceptable reduction in risk can be achieved with a fairly small number of hedging assets (Kennedy et al., 2009).

\subsection{Harvesting model for the RSMR case}

We model the optimal decision of the owner of stand of trees who wants to maximize the value of the stand (or land value) by optimally choosing the harvest time. It is assumed that forestry is the best use for this land, so that once the stand is harvested it will be allowed to grow again for future harvesting. Since this is a multirotational optimal harvesting problem, it represents a path-dependent option. The value of the option to harvest the stand today depends on the quantity of lumber, which itself depends on the last time when the stand was harvested.

Lumber price is assumed to follow either the RSMR model or the TMR model detailed in the previous sections. In this section we derive the key partial differential equation that describes the value of the stand of trees for the RSMR case. Derivation of the key partial differential equation for the TMR case can be found in Insley and Lei (2007).

For now we write the RSMR model from Equation (2) in a more general form as:

$$
d P\left(s_{t}\right)=a\left(s_{t}, P, t\right) d t+b\left(s_{t}, P, t\right) d Z
$$

Denote $q^{s_{t} \rightarrow 1-s_{t}}$, the risk of regime shift, as a Poisson process, where $s_{t} \in\{0,1\}$ indicates 
the regime.

$$
\begin{aligned}
& d q^{s_{t} \rightarrow 1-s_{t}}=1 \quad \text { with probability } \lambda^{s_{t} \rightarrow 1-s_{t}} d t \\
& d q^{s_{t} \rightarrow 1-s_{t}}=0 \quad \text { with probability } 1-\lambda^{s_{t} \rightarrow 1-s_{t}} d t
\end{aligned}
$$

With probability $\lambda d t$ price changes regime during the small interval $d t$, and with probability $1-\lambda d t$ price remains in the same regime.

There are two risks associated with this stochastic process. One is the standard continuous risk in the $d Z$ term. The other, in discrete form, is due to the risk of regime switch. In order to hedge these two risks and value the stand of trees $V\left(s_{t}, P, \varphi\right)$, two other traded investment assets, which depend solely on lumber price, are needed. Let $\varphi$ denote the age of the stand, defined as $\varphi=t-t_{h}$, where $t_{h}$ represents the time of last harvest. $\varphi$ in this case is another state variable, in addition to $P . \varphi$ satisfies $d \varphi=d t$.

Assume that there exist investment assets which depend on the lumber price $P$ and can be used to hedge the risk of our investment. Using standard arguments we set up a hedging portfolio that eliminates the two risks. We can derive the fundamental partial differential equation that characterizes the value of the stand of trees when it is optimal to refrain from harvesting.

$$
\begin{array}{r}
V\left(s_{t}\right)_{t}+\left(a\left(s_{t}, P, t\right)-\beta_{P} b\left(s_{t}, P, t\right)\right) V\left(s_{t}\right)_{P}+\frac{1}{2} b\left(s_{t}, P, t\right)^{2} V\left(s_{t}\right)_{P P}+ \\
V\left(s_{t}\right)_{\varphi}-r V\left(s_{t}\right)+\beta_{s w}\left(V\left(1-s_{t}\right)-V\left(s_{t}\right)\right)=0
\end{array}
$$

$\beta_{P}$ and $\beta_{s w}$ are parameters which represent market prices of risk for the diffusion risk and regime-switching risk respectively.

Our estimation method detailed in Sections 4 and 5 yields risk neutral parameter values. Therefore the following relationships hold

$$
\begin{aligned}
a\left(s_{t}, P, t\right)-\beta_{P} b\left(s_{t}, P, t\right) & =\alpha\left(s_{t}\right)\left(K\left(s_{t}\right)-P\right) \\
b\left(s_{t}, P, t\right) & =\sigma\left(s_{t}\right) P \\
\beta_{s w} & =\lambda^{s_{t} \rightarrow 1-s_{t}}
\end{aligned}
$$


Substituting these equations into the above PDE give

$$
\begin{array}{r}
V\left(s_{t}\right)_{t}+\alpha\left(s_{t}\right)\left(K\left(s_{t}\right)-P\right) V\left(s_{t}\right)_{P}+\frac{1}{2}\left(\sigma\left(s_{t}\right) P\right)^{2} V\left(s_{t}\right)_{P P}+V\left(s_{t}\right)_{\varphi}-r V\left(s_{t}\right)+ \\
\lambda^{s_{t} \rightarrow 1-s_{t}}\left(V\left(1-s_{t}\right)-V\left(s_{t}\right)\right)=0 .
\end{array}
$$

The complete harvesting problem which determines the optimal harvesting date can then be specified as a Hamilton-Jacobi-Bellman (HJB) variational inequality (VI). Define $\tau \equiv T-t$ as time remaining in the option's life. Rewrite the above PDE and define $H V$ as

$$
\begin{array}{r}
H V \equiv r V\left(s_{t}\right)-\left(V\left(s_{t}\right)_{t}+\alpha\left(s_{t}\right)\left(K\left(s_{t}\right)-P\right) V\left(s_{t}\right)_{P}+\frac{1}{2}\left(\sigma\left(s_{t}\right) P\right)^{2} V\left(s_{t}\right)_{P P}+V\left(s_{t}\right)_{\varphi}+\right. \\
\left.\lambda^{s_{t} \rightarrow 1-s_{t}}\left(V\left(1-s_{t}\right)-V\left(s_{t}\right)\right)\right)
\end{array}
$$

Then the HJB VI is:

$$
\begin{array}{ll}
\text { (i) } & H V \geq 0 \\
\text { (ii) } & V\left(s_{t}, P, \varphi\right)-\left[\left(P-C_{h}\right) Q(\varphi)+V\left(s_{t}, P, 0\right)\right] \geq 0 \\
\text { (iii) } & H V\left[V\left(s_{t}, P, \varphi\right)-\left[\left(P-C_{h}\right) Q(\varphi)+V\left(s_{t}, P, 0\right)\right]\right]=0
\end{array}
$$

where $C_{h}$ is the cost per unit of lumber, $Q(\varphi)$ is the volume of the lumber which is a function of age, $Q=g(\varphi)$. $\left[\left(P-C_{h}\right) Q(\varphi)+V\left(s_{t}, P, 0\right)\right]$ is the payoff from harvesting immediately and consists of revenue from selling the harvested timber plus the value of the bare land, $V\left(s_{t}, P, 0\right)$. The above HJB VI implies if the stand of trees is managed optimally either $H V, V\left(s_{t}, P, \varphi\right)-\left[\left(P-C_{h}\right) Q(\varphi)+V\left(s_{t}, P, 0\right)\right]$, or both will be equal to zero. If $H V=0$, it is optimal for the investor to continue holding the option by delaying the decision to harvest. The growing stand of trees is earning the risk free return. If $V\left(s_{t}, P, \varphi\right)-\left[\left(P-C_{h}\right) Q(\varphi)+V\left(s_{t}, P, 0\right)\right]=0$, then the value of the stand of trees just equals the value of immediate harvest and the investor should harvest the trees. If both terms are equal to zero, either strategy is optimal. 


\subsection{Numerical solution of the HJB VI equation}

This section briefly describes the numerical methods used for solving the regime switching HJB VI, Equation (27). We also analyze the properties of the scheme, such as the stability and monotonicity. More details of the numerical solution are contained in Appendix B.

\subsubsection{General description of the numerical methods}

The option to choose the optimal harvest time has no analytical solution. The HJB VI expressed in Equation (27) in this paper is solved numerically using the combination of fully implicit finite difference method, semi-Lagrangian method and the penalty method. This approach is also used in Insley and Lei (2007) but for a single regime problem. The finite difference method is used to convert a differential equation into a set of discrete algebraic equations by replacing the differential operators in PDEs with finite difference operators.

For the optimal tree harvesting problem examined in this paper, there are two state variables. One is the spot price $P$ and the other is the stand age $\varphi$. Using the semiLagrangian method this two-factor problem can be reduced to a one factor problem for each time step. After each time step, the true option value is obtained by using linear interpolation. For the details of this method, see Insley and Rollins (2005) and Morton and Mayers (1994).

There are several approaches to the numerical solution of the HJB VI. The penalty approach used here converts it into a nonlinear algebraic problem, which is then solved by Newton iteration. The penalty method has several benefits. It is more accurate than an explicit method and has good convergence properties. Another advantage is that at each iteration it generates a well-behaved sparse matrix, which can be solved using either direct or iterative methods. ${ }^{16}$

The penalty method used in this paper is outlined here. Define $\tau=T-t$ and $V\left(s_{t}\right)_{t}=$

\footnotetext{
${ }^{16}$ See Zvan et al. (1998) and Fan et al. (1996) for more on the penalty method.
} 
$-V\left(s_{t}\right)_{\tau}$. The HJB $\mathrm{VI}^{17}$ in Equation (27) can be expressed as a single equation:

$$
\begin{array}{r}
V\left(s_{t}\right)_{\tau}-V\left(s_{t}\right)_{\varphi}=\alpha\left(s_{t}\right)\left(K\left(s_{t}\right)-P\right) V\left(s_{t}\right)_{P}+\frac{1}{2}\left(\sigma\left(s_{t}\right) P\right)^{2} V\left(s_{t}\right)_{P P}-r V\left(s_{t}\right)+ \\
\lambda^{s_{t} \rightarrow 1-s_{t}}\left(V\left(1-s_{t}\right)-V\left(s_{t}\right)\right)+\Upsilon\left(s_{t}\right)
\end{array}
$$

where $\Upsilon\left(s_{t}\right)$ on the right hand side of this equation is the penalty term, which satisfies

$$
\begin{aligned}
\Upsilon\left(s_{t}\right) & >0 \text { if } V\left(s_{t}, P, \varphi\right)=\left[\left(P-C_{h}\right) Q(\varphi)+V\left(s_{t}, P, 0\right)\right] \\
& =0 \text { if } V\left(s_{t}, P, \varphi\right)>\left[\left(P-C_{h}\right) Q(\varphi)+V\left(s_{t}, P, 0\right)\right]
\end{aligned}
$$

Equation (29) implies that if value of the asset equals to the payoff, which is $\left[\left(P-C_{h}\right) Q(\varphi)+\right.$ $\left.V\left(s_{t}, P, 0\right)\right]^{18}$, it is optimal to harvest the trees immediately, which is the first condition in HJB VI Equation (27). If the asset value is higher than the payoff, Equation (30) implies the harvest should be delayed which is the second condition in the HJB VI equation. The penalty method in this way incorporates the American constraint.

A complicating factor in our problem is the presence of regime switching in the spot price process. We have two PDEs in the form of Equation (25), one for the value in each of the two regimes. Moreover, the value in one regime affects the value in the other regime ${ }^{19}$. We deal with this problem by stacking the discretized version of equation (28) for option values in two regimes and solving the two discretized PDEs together at each time step. In this manner the PDEs in the two regimes are fully coupled.

\subsubsection{Discretization}

This section illustrates the main results of finite difference discretization, the semi-Lagrangian method and penalty method of dealing with the $\mathrm{HJB} \mathrm{VI}^{20}$. Prior to presenting the matrix form of the HJB VI discretization, some notation is introduced here.

For PDE discretization, unequally spaced grids in the directions of the two state variables

${ }^{17}$ This HJB VI characterizes the option value in regime $s_{t}, V\left(s_{t}\right)$.

${ }^{18}$ The payoff is defined as the net revenue of selling the trees plus the value of the bare land.

19 i.e. The value in regime $\left(1-s_{t}\right), V\left(1-s_{t}\right)$, appears in Equation $(25)$ characterizing the option value in regime $s_{t}, V\left(s_{t}\right)$.

${ }^{20}$ Detailed discretization is provided in Appendix. 
$P$ and $\varphi$ are used. The grid points are represented by $\left[P_{1}, P_{2}, \ldots, P_{\text {imax }}\right]$ and $\left[\varphi_{1}, \varphi_{2}, \ldots, \varphi_{\text {jmax }}\right]$ respectively. We also discretize the time direction, represented as $\left[\tau^{N}, \ldots, \tau^{1}\right] .{ }^{21}$ Define $V\left(s_{t}\right)_{i j}^{n+1}$ as an approximation of the exact solution $V\left(s_{t}, P_{i}, \varphi_{j}, \tau^{n+1}\right)$, and $V^{*}\left(s_{t}\right)_{i j}^{n}$ as an approximation of $V\left(s_{t}, P_{i}, \varphi_{j}, \tau^{n}\right)$. Recall that $\tau=\tau^{N}, t=0$ and at $\tau=\tau^{1}, t=T$. Based on the semi-Lagrangian method, the true solution of $V\left(s_{t}, P_{i}, \varphi_{j+\Delta \tau}, \tau^{n}\right)$ is obtained from $V^{*}\left(s_{t}\right)_{i j}^{n}$ using linear interpolation after each time step.

Denote $\ell$ a differential operator represented by

$$
\ell V\left(s_{t}\right)=\alpha\left(s_{t}\right)\left(K\left(s_{t}\right)-P\right) V\left(s_{t}\right)_{P}+\frac{1}{2}\left(\sigma\left(s_{t}\right) P\right)^{2} V\left(s_{t}\right)_{P P}-r V\left(s_{t}\right)
$$

Equation (28) can be rearranged as:

$$
V\left(s_{t}\right)_{\tau}-V\left(s_{t}\right)_{\varphi}=\ell V\left(s_{t}\right)+\lambda^{s_{t} \rightarrow 1-s_{t}} V\left(1-s_{t}\right)+\Upsilon\left(s_{t}\right)
$$

Note that the right hand side of this equation has derivatives with respect to $P$ only. Therefore this one-dimensional PDE for each $\varphi_{j}$ is solved independently within each time step. After each time step is completed, using linear interpolation we will get $V\left(s_{t}, P_{i}, \varphi_{j+\Delta \tau}, \tau^{n}\right)$ from $V^{*}\left(s_{t}\right)_{i j}^{n}$. The discretized version of Equation (31) using the fully implicit method and the semi-Lagrangian method is written as

$$
\frac{V\left(s_{t}\right)_{i j}^{n+1}-V^{*}\left(s_{t}\right)_{i j}^{n}}{\Delta \tau}=\left[\ell V\left(s_{t}\right)\right]_{i j}^{n+1}+\lambda^{s_{t} \rightarrow 1-s_{t}} V\left(1-s_{t}\right)_{i j}^{n+1}+\pi\left(s_{t}\right)_{i j}^{n+1}
$$

where the penalty term $\pi\left(s_{t}\right)_{i j}^{n+1}$ is defined as

$$
\begin{aligned}
\pi\left(s_{t}\right)_{i j}^{n+1} & =\frac{1}{\Delta \tau}\left(\text { payoff }-V\left(s_{t}\right)_{i j}^{n+1}\right) \text { Large; if } V\left(s_{t}\right)_{i j}^{n+1}<\text { payoff } \\
& =0 ; \text { otherwise }
\end{aligned}
$$

The term 'Large' in equation (33) refers to a large number ${ }^{22}$ and case dependent. The subscript $i j$ refers to the point corresponding to $\left(P_{i}, \varphi_{j}\right)$ and superscript $n$ denotes the $n$th

\footnotetext{
${ }^{21}$ The iteration starts from the final maturity date $T$ and moves backward along the time direction until the current time 0 .

${ }^{22}$ For example, Large $=10^{6}$ for some cases.
} 
time step.

Rearranging Equation (32) and writing in a matrix form results in

$$
W\left(s_{t}\right) V\left(s_{t}\right)^{n+1}-\Delta \tau \lambda^{s_{t} \rightarrow 1-s_{t}} V\left(1-s_{t}\right)^{n+1}=V^{*}\left(s_{t}\right)^{n}+{\overline{\pi\left(s_{t}\right.}}^{n+1} \operatorname{payoff}\left(s_{t}\right)^{n+1}
$$

where $W\left(s_{t}\right)$ is a sparse matrix containing all the parameters corresponding to the value in regime $s_{t}$. The other terms except $\Delta \tau \lambda^{s_{t} \rightarrow 1-s_{t}}$ are expressed in vector form. The $i j$ th element in the penalty vector ${\overline{\pi\left(s_{t}\right)}}^{n+1}$ is defined as

$$
\begin{aligned}
{\overline{\pi\left(s_{t}\right)}}_{i j}^{n+1} & =\text { Large; if } V\left(s_{t}\right)_{i j}^{n+1}<\text { payoff } \\
& =0 ; \text { otherwise }
\end{aligned}
$$

Equation (35) is the final discretized version of the HJB VI corresponding to $V\left(s_{t}\right)$. However, the value in the other regime $V\left(1-s_{t}\right)$ appears in this expression. In order to obtain both option values for all the grid points at each time step, the discretized HJB VI for $V\left(1-s_{t}\right)$ which is similar with the expression (35) is stacked with Equation (35) to form a system of equations, which can be written as

$$
Z_{\text {matrix }}\left[\begin{array}{c}
V\left(s_{t}\right) \\
V\left(1-s_{t}\right)
\end{array}\right]^{n+1}=\left[\begin{array}{c}
V^{*}\left(s_{t}\right) \\
V^{*}\left(1-s_{t}\right)
\end{array}\right]^{n}+\left[\begin{array}{c}
\overline{\pi\left(s_{t}\right)} \\
\overline{\pi\left(1-s_{t}\right)}
\end{array}\right]^{n+1}\left[\begin{array}{c}
\operatorname{payoff}\left(s_{t}\right) \\
\operatorname{payoff}\left(1-s_{t}\right)
\end{array}\right]^{n+1}
$$

$Z_{\text {matrix }}$ is a large sparse matrix. This system of equations is solved iteratively at each time step. For simplicity, the more compact version of Equation (36) can be expressed as

$$
Z_{\text {matrix }}[V]^{n+1}=\left[V^{*}\right]^{n}+[\bar{\pi}]^{n+1}[\text { payoff }]^{n+1}
$$

This is the scheme we use to numerically solve the optimal tree harvesting problem.

\subsubsection{Boundary conditions and pseudo code}

In order to solve Equation (37), the appropriate boundary conditions as well as the terminal condition are specified below. These are the same as used in Insley and Rollins (2005). 
1. As $\boldsymbol{P} \rightarrow \mathbf{0}$, no specific boundary condition is needed. Substitute $P=0$ into Equation (37) and discretize the resulted PDE.

2. As $\boldsymbol{P} \rightarrow \infty$, we set $V\left(s_{t}\right)_{P P}=0$. As price goes to infinity, we assume the option value is a linear function of $P$.

3. As $\boldsymbol{\varphi} \rightarrow \mathbf{0}$, no specific boundary condition is needed since the $\mathrm{PDE}$ is first order hyperbolic in the $\varphi$ direction, with outgoing characteristic in the negative $\varphi$ direction.

4. As $\varphi \rightarrow \infty, V\left(s_{t}\right)_{\varphi} \rightarrow 0$, and hence no boundary condition is needed. Since as the stand age goes to infinity, we assume the wood volume in the stand has reached some a steady state and the value of the option to harvest does not change with $\varphi$.

5. Terminal condition. $V\left(s_{t}, T\right)=0$ This means when $T$ gets very large, it has a negligible effect on the current option value.

Pseudo code for solving Equation (37) is provided as the follows ${ }^{23}$.

${ }^{23}$ All programs are written in Matlab. 
1. Set up tolerance level tol

2. Large $=\frac{1}{\text { tol }}$

3. for $\tau=1: N-1 ; \%$ time step iteration

for $j=1: j \max ; \%$ iterate along the age $\varphi$ direction

$\left([V]^{n+1}\right)^{0}=[V]^{n} ; \%$ initial guess for $[V]^{n+1}$

for $k=0, \ldots$ until convergence; \% penalty American constraint iteration

$$
\begin{aligned}
\left(\bar{\pi}^{n+1}\right)^{k} & =\text { Large; if } V^{n+1}<\text { payoff } \\
& =0 ; \text { otherwise }
\end{aligned}
$$

$Z_{\text {matrix }}\left([V]^{n+1}\right)^{k+1}=\left[V^{*}\right]^{n}+\left([\bar{\pi}]^{n+1}\right)^{k}[\text { payoff }]^{n+1}$

if $\max _{i} \frac{\left|\left(\left(V_{i}\right)^{n+1}\right)^{k+1}-\left(\left(V_{i}\right)^{n+1}\right)^{k}\right|}{\max \left(1,\left|\left(\left(V_{i}\right)^{n+1}\right)^{k+1}\right|\right)}<$ tol

quit;

endfor; \% end penalty American constraint iteration

endfor; $\%$ end iteration along $\varphi$ direction

$V\left(s_{t}, P_{i}, \varphi_{j+\Delta \tau}, \tau^{n}\right)=V^{*}\left(s_{t}\right)_{i j}^{n} ; \%$ by linear interation

endfor; \% end time step iteration

\subsubsection{Properties of the numerical scheme}

Since no closed-form solution exists for our optimal tree harvesting problem, the properties of our proposed numerical scheme have to been examined. In the case of nonlinear pricing problems, seemingly reasonable numerical schemes can converge to an incorrect solution ${ }^{24}$. A stable, consistent and monotone discretization will converge to the viscosity (i.e. reasonable) solution. ${ }^{25}$. Generally speaking, consistency is guaranteed if a reasonable discretization is used $^{26}$. We use finite difference discretization which is a one of the standard discretization methods. In Appendix C, we prove that our scheme is monotone and stable and thus converges to the viscosity solution which is financially reasonable.

\footnotetext{
${ }^{24}$ See Pooley et al. (2003).

${ }^{25}$ See Barles (1997) for detailed proof. For the definition of viscosity solution, see d'Halluin et al. (2005). For the existence of a viscosity solution in the regime switching case, see Pemy and Zhang (2006).

${ }^{26}$ See d'Halluin et al. (2005).
} 


\begin{tabular}{c|c|c}
\hline \hline Item & Cost, $\$ /$ ha & Age cost incurred \\
\hline Site preparation & $\$ 200$ & 1 \\
Nursery stock & $\$ 360$ & 1 \\
Planting & $\$ 360$ & 2 \\
First tending & $\$ 120$ & 5 \\
Monitoring & $\$ 10$ & 35 \\
\hline \hline
\end{tabular}

TABle 5: Silviculture costs under a basic regime

\section{Optimal harvesting problem: data and empirical re- sults}

\subsection{Cost, wood volume and price data}

We examine an optimal harvesting problem for a hypothetical stand of Jack Pine trees in Ontario's boreal forest. We consider the optimal harvesting decision and land value assuming that the stand will continue to be used for commercial forestry operations over multiple rotations. Values are calculated prior to any stumpage payments or taxes.

Timber volumes and harvesting costs are adopted from Insley and Lei (2007) and are repeated here for the convenience of the reader. Volume and silviculture cost data were kindly provided by Tembec Inc. The estimated volumes reflect 'basic' levels of forestry management which involves $\$ 1040$ per hectare spent within the first five years on site preparation, planting and tending. These costs are detailed in Table 5. Note that in the Canadian context these basic silviculture expenses are mandated by government regulation for certain stands.

Volumes, estimated by product, are shown in Figure 5 for the basic silviculture regime. ${ }^{27}$ SPF1 and SPF2 are defined as being greater than 12 centimeters at the small end, SPF3 is less than 12 centimeters, and 'other' refers to other less valuable species (poplar and birch). Data used to plot this graph is provided in Insley and Wirjanto (2010).

Assumptions for harvesting costs and current log prices at the millgate are given in Table 6. These prices are considered representative for 2003 prices at the millgate in Ontario's boreal forest. Average cost to deliver logs to the lumber mill in 2003 are reported as $\$ 55$ per cubic meter in a recent Ontario government report Ontario Ministry of Natural Resources

\footnotetext{
${ }^{27}$ The yield curves were estimated by Margaret Penner of Forest Analysis Ltd., Huntsville, Ontario for Tembec Inc.
} 


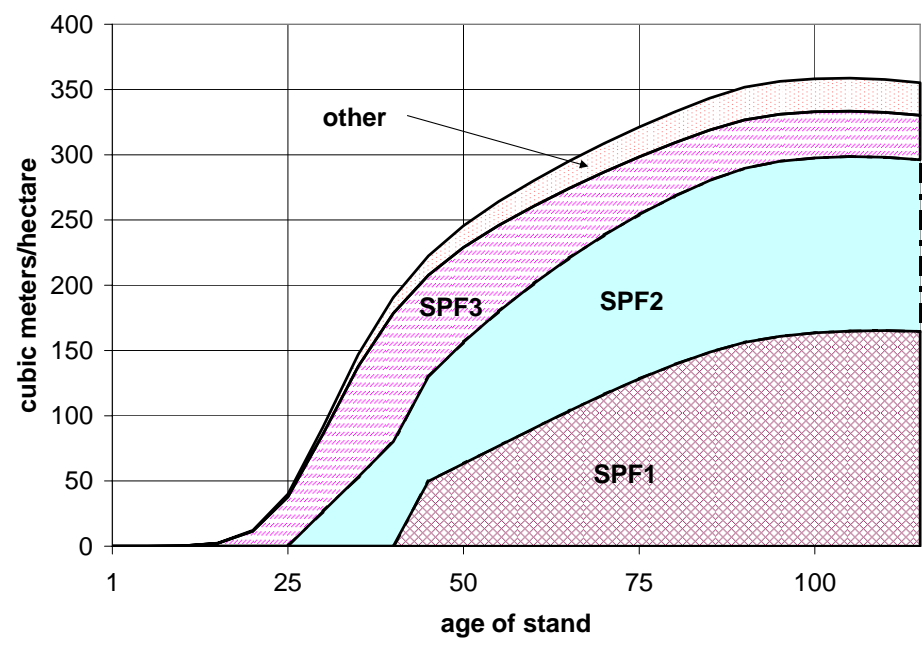

FiguRE 5: Volumes by product for hypothetical Jack Pine stands in Ontario's boreal forest under basic management

\begin{tabular}{c|c}
\hline \hline Harvest and transportation cost & $\$ 47$ \\
Price of SPF1 & $\$ 60$ \\
Price of SPF2 & $\$ 55$ \\
Price of SPF3 & $\$ 30$ \\
Price of poplar/birch & $\$ 20$ \\
\hline
\end{tabular}

TABLE 6: Assumed values for log prices and cost of delivering logs to the mill in \$ per cubic meter

(2005). From this is subtracted $\$ 8$ per cubic meter as an average stumpage charge in 2003 giving $\$ 47$ per cubic meter. ${ }^{28}$ It will be noted the lower valued items (SPF3 and poplar/birch) are harvested at a loss. These items must be harvested according to Ontario government regulation. The price for poplar/birch is at roadside, so there is no transportation cost to the mill.

\footnotetext{
${ }^{28}$ This consists of $\$ 35$ per cubic meter for harvesting and $\$ 12$ per cubic meter for transportation. Average stumpage charges are available from the Ontario Ministry of Natural Resources.
} 


\begin{tabular}{c|c|c|c}
\hline Land value in $\$$ per hectare, Initial lumber price of $\$ 60 / \mathrm{m}^{3}$ \\
\hline \hline \multicolumn{3}{c}{ RSMR model } & TMR model \\
\hline Initial Stand age & Regime 0 & Regime 1 & Single regime \\
Age 0 & 2858 & 2858 & 1404 \\
Age 50 & 10593 & 10728 & 5617 \\
Age 75 & 13406 & 13660 & 9078 \\
\hline \multicolumn{3}{c}{} \\
Land value in \$ per hectare, Initial lumber price of $\$ 100 / \mathrm{m}^{3}$ \\
\hline \hline \multicolumn{3}{c}{ RSMR model } & TMR model \\
\hline Initial Stand age & Regime 0 & Regime 1 & Single regime \\
Age 0 & 2858 & 2858 & 1404 \\
Age 50 & 11503 & 12242 & 7474 \\
Age 75 & 15352 & 16619 & 13896 \\
\hline
\end{tabular}

TABLE 7: Land values at the beginning of the first rotation for regime switching and traditional mean reversion models, \$(2005)Canadian per hectare

\subsection{Results for land value and critical harvesting prices}

The parameter values of the RSMR model used to evaluate the investment are provided in previous sections. The equilibrium price levels in the two regimes, $K\left(s_{t}\right)$, as shown in Table 2 , are stated in Canadian dollars at Toronto. In order to value our hypothetical stand of trees, the equilibrium prices need to be scaled to reflect prices at the millgate. Our estimate of price at the millgate in 2003 for SPF1 logs is Cdn.\$60 per cubic meter. In 2003 the average spot price in Toronto was Cdn. $\$ 375$ per MBF. We use the ratio of 375/60 as adjustment factor to scale the equilibrium price levels. The scaled long-run price levels become $K(0)=\$ 11.51$ and $K(1)=\$ 82.66$ per cubic metre. This rescaling accounts for transportation costs from Toronto to the mill and milling costs (as well as the conversion from MBF to $\mathrm{m}^{3}$ ).

Land values calculated using the RSMR and TMR models are provided in Table 7 for three different initial stand ages and two initial lumber prices. For the RSMR model, the value of the opportunity to harvest a stand at the beginning of rotation (stand age of zero) is $\$ 2858$ per hectare in either regime 1 or 2 regime and for both initial price levels shown. This reflects the fact that at the beginning of the rotation the harvest date is many years away and regime switching will likely happen numerous times over the next few decades. Hence the current regime has little effect on land value at the beginning of the rotation. Similarly the current price has a negligible effect on the value of the bare land. For older stands for 


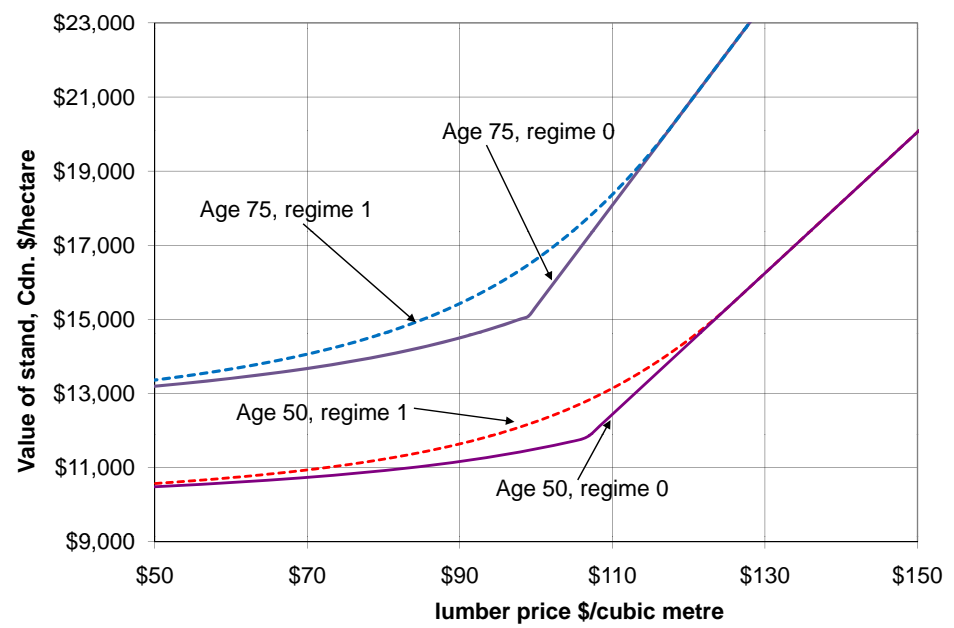

FiguRE 6: Land values for different aged stands in the RSMR case. Dashed lines: Regime 1, solid lines: Regime 0

which the optimal harvesting time is nearer, the value of the stand does depend positively on the current price of lumber. Further, the stand value is slightly higher in regime 1 than in regime 0 . In Table 7 , we observe that at an initial price of $\$ 100 / \mathrm{m}^{3}$ the land value in regime 1 is approximately $8 \%$ higher than in regime 0 . Another perspective on land values for older stands is given in Figure 6. Here we see that land values for 50 and 75 year old stands rise with lumber price and that for a range of prices values in regime 1 exceeds values in regime 0 . As will be seen below, this price range is around the critical price level that would trigger optimal harvesting.

The value of land in the TMR regime, also shown in Table 7 , is $\$ 1404$ per hectare at age 0 , significantly lower than in the RSMR case. This is because, for the RSMR model, the calibrated mean price level in regime 1 is higher than that of the corresponding one-factor TMR model. Further, the price in the regime switching model stays in the high mean regime most of time giving a higher land value for the RSMR case.

For comparison purposes we note that the land value for the same stand at age 0 calculated in Insley and Lei (2007) was $\$ 1630 /$ ha. The analysis in Insley and Lei (2007) uses the 
same cost and yield data, with a TMR process. However the parameters of the TMR process were estimate through OLS on spot price data and the market price of risk was estimated separately in a more simplistic manner.

Critical harvesting prices versus stand age are shown in Figure 7. For a stand of a given age, once the critical harvesting price is met or surpassed, harvesting of the stand and replanting for the next rotation are the optimal actions. Harvesting is not permitted in the model prior to age 35 until all silviculture expenditures have been made.

Critical prices are high during the earlier ages when the trees are still growing, but fall as the stand ages and eventually reach a steady state. Critical prices are highest for Regime 1 which is characterized by a high equilibrium level and a slower speed of mean reversion. Since volatility is at a moderate level of 0.25 and the probability of switching out of this regime is low, it is worthwhile delaying harvesting until a higher threshold is reached. In contrast in regime 0 , the speed of mean reversion is faster and the equilibrium level is lower so that when in that regime it is expected that price will return fairly quickly to the low equilibrium level. In addition volatility in this regime is very low which reduces the value of delay. Offsetting this is a high likelihood of switching into the higher priced regime. Overall the critical prices of this regime are below those of Regime 1 at every age.

Critical prices for the TMR case are consistently below those of the two regimes in the RSMR model. This makes intuitive sense given that the long run equilibrium level is lower in the TMR case than in the high price regime (Regime 1) and that unlike in Regime 0, there is no potential to switch into a different regime with a higher long run equilibrium level.

In summary, the regime switching model results in different land values and leads to significantly different investment strategies than the corresponding single-factor models. Our calibration results show the regime switching model outperforms the single regime model in terms of fitting lumber market prices. Moreover the regime switching model generates reasonable stand values as well as the critical prices. We would argue that the regime switching model is preferred in the analysis of forestry investment decisions and land valuation. 


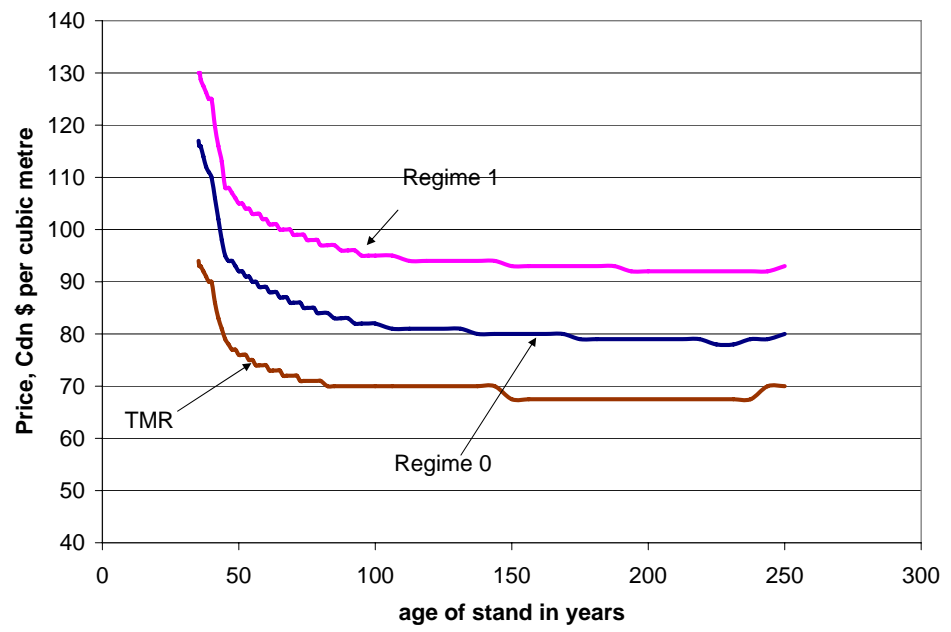

FiguRE 7: Critical harvesting prices for the RSMR and TMR cases

\section{Concluding remarks}

Understanding forest valuation is important for policy makers, forestry firms and investors. In the Canadian situation, harvesting rights to specific areas of publicly owned forests are leased to private firms. Government regulators need to be aware of the value of these harvesting rights in order to ensure the public is compensated for the use of the resource and in order to gauge the impact of regulatory changes on the profitability of forestry operations. And of course private players in the industry also have an incentive to understand the impact of volatile prices on land values and optimal decisions, as well as changes that might result from regulatory decisions such as a requirement to increase spending on replanting or other conservation measures.

This paper investigates a possible improvement in the modelling of stochastic timber prices in optimal tree harvesting problems. Our goal is to find a modelling approach that is rich enough to capture the main characteristics of timber prices, while still being simple enough that the resulting price model can easily be incorporated into problems of forest investment valuation. We compare two different stochastic price process, a regime switching 
model with a different mean reverting process in each regime (RSMR) and a traditional mean reverting model (TMR). The RSMR model allows for two states in lumber markets which we may characterize as being good times and bad times. The price models are calibrated using lumber futures prices and futures call option prices. The calibration process is able to find a reasonable fit for both models, but the mean absolute error is lower for the RSMR model.

In the second part of the paper, we use the calibrated timber price models in a real options model of the optimal harvesting decision. PDEs characterizing the value of the stand of trees are derived using contingent claim analysis. A Hamilton-Jacobi-Bellman (HJB) variational inequality is then developed and solved using a fully implicit numerical method. We show that our numerical scheme converges to the viscosity solution (i.e. the financially reasonable solution.)

Our empirical example is for a hypothetical stand of trees in Ontario's boreal forest. For the RSMR model, the estimated land value at the beginning of the rotation is insensitive to the particular regime and at $\$ 2858$ per hectare is of a reasonable order of magnitude. The land value for the TMR model is $\$ 1404$ per hectare. We also examined critical harvesting prices, which for the RSMR model differ depending on the current regime.

We conclude that the RSMR model shows some promise as a parsimonious model of timber prices, that can fairly easily be incorporated into optimal harvesting models. One limitation of our methodology is in the use of short term maturity contracts in the calibration exercise. The longest maturity of the chosen futures contract is less than one year, but unfortunately this is all that is available. One may ask whether the calibrated parameter values are appropriate for long term forestry investment valuation problems. Schwartz and Smith (2000) has proposed a way of dealing with this issue. The applicability of his method for lumber prices is an area for future research.

Future research will also investigate the robustness of the RSMR model through comparison with other multi-factor models that have been used in the literature to value other commodity linked investments. We hope that other researchers will find the methodologies demonstrated here useful for the analysis of other types of investments, particularly those dependent on commodity prices where active futures markets exist. 


\section{References}

Alvarez, L. H. and E. Koskela (2005). Wicksellian theory of forest rotation under interest rate variablity. Journal of Economic Dynamics and Control 29, 529-545.

Alvarez, L. H. and E. Koskela (2007). Taxation and rotation age under stochastic forest stand value. Journal of Environmental Economics and Management 54, 113-127.

Baker, M., S. Mayfild, and J. Parsons (1998). Alternative models of uncertain commodity prices for use with modern asset pricing methods. The Energy Journal 19, 115-148.

Barles, G. (1997). Convergence of numerical schemes for degenerate parabolic equations arising in finance. In L. Rogers and D. Talay (Eds.), Numerical Methods in Finance, pp. 1-21. Cambridge University Press.

Bessembinder, H., J. F. Coughenour, S. Paul, and M. M. Smoller (1995). Mean-reversion in equilibrium asset prices: Evidence from the futures term structure. Journal of Finance 50, $361-375$.

Brazee, R. J., G. Amacher, and M. Conway (1999). Optimal harvesting with autocorrelated stumpage prices. Journal of Forest Economics 5, 193-200.

Caulfield, J. P. and D. H. Newman (1999). Dealing with timberland investment risk: Theory versus practice for institutional owners. Journal of Forest Economics 5, 253-268.

Chen, Z. and P. A. Forsyth (2008). Implications of a regime-switching model on natural gas storage valuation and optimal operation. Quantitative Finance. forthcoming.

Clarke, H. and W. Reed (1989). The tree-cutting problem in a stochastic environment. Journal of Economic Dynamics and Control 13, 569-95.

Cortazar, G. and E. S. Schwartz (1994). The valuation of commodity contingent claims. Journal of Derivatives 1, 27-39.

Davies, R. (1977). Hypothesis testing when a nuisance parameter is present only under the alternative. Biometrika 64, 247-254.

Davies, R. (1987). Hypothesis testing when a nuisance parameter is present only under the alternative. Biometrika 74, 33-43.

de Jong, C. (2005). The nature of power spikes: a regime-switching approach. Technical report, Rotterdam School of Management at Erasmus University.

Deng, S. (2000). Stochastic models of energy commodity prices and their applications: mean reversion with jumps and spikes. Technical report, University of California Energy Institute.

d'Halluin, Y., P. Forsyth, and G. Labahn (2005). A semi-lagrangian approach for american asian options under jump diffusion. SIAM Journal on Scientific Computing 27, 315-345. 
Dixit, A. K. and R. S. Pindyck (1994). Investment under uncertainty. Princeton University Press, Princeton, NJ.

Fan, Q., P. Forsyth, J. McMacken, and W. Tang (1996). Performance issues for iterative solvers in device simulation. SIAM Journal on Scientific and Statistical Computing 19, $100-117$.

Geman, H. (2005). Commodities and commodity derivatives: Modelling and Pricing for Agriculturals, Metals and Energy. John Wiley \& Sons, Ltd, West Sussex, England.

Global Institute of Sustainable Forestry (2002). Institutional timberland investment. Technical Report 2, Yale Forest Forum, New Haven, Connecticut.

Gong, P. (1999). Optimal harvest policy with first-order autoregresive price process. Journal of Forest Economics 5, 413-439.

Grimmett, G. and D. Stirzaker (2001). Probability and Random Processes, third edition. Oxford University Press.

Hamilton, J. (1989). A new approach to the economic analysis of non-stationary time series and the business cycle. Econometrica 57, 357-384.

Insley, M. and M. Lei (2007). Hedges and trees: Incorporating fire risk into optimal decisions in forestry using a no-arbritrage approach. Journal of Agricultural and Resource Economics 32, 492-514.

Insley, M. and K. Rollins (2005). On solving the multirotational timber harvesting problem with stochastic prices: a linear complemetarity formulation. American Journal of Agricultural Economics $8 \%$.

Insley, M. and T. Wirjanto (2010). Contrasting two approaches in real options valuation: contingent claims versus dynamic programming. Journal of Forest Economics 16(2), 157176.

Kennedy, J. (2007). Hedging contingent claims in markets with jumps. Ph. D. thesis, University of Waterloo.

Kennedy, J., P. Forsyth, and K. Vetzal (2009). Dynamic hedging under jump diffusion with transaction costs. Operations Research 57, 541-559.

Lam, P. (1990). The hamilton model with a general autoregressive component. Journal of Monetary Economics 26, 409-432.

Lucia, J. and E. S. Schwartz (2002). Electricity prices and power derivatives:evidence from the nordic power exchange. Review of Derivatives Research 5, 5-50.

Merton, R. (1976). Option pricing when underlying stock returns are dicontinuous. Journal of Financial Economics 3, 125-144. 
Morck, R., E. Schwartz, and D. Strangeland (1989). The valuation of forestry resources under stochastic prices and inventories. Journal of Financial and Quantitative Analysis 4, $473-487$.

Morton, K. and D. Mayers (1994). Numerical solution of partial differential equations). Cambridge University Press, Cambridge.

Naik, V. (1993). Option valuation and hedging strategies with jumps in the volatility of asset returns. Journal of Finance XLVIII, 1969-1984.

Ontario Ministry of Natural Resources (May, 2005). Minister's Council on Forest Sector Competitivenes, Final Report.

Pemy, M. and Q. Zhang (2006). Optimal stock liquidation in a regime switching model with finite time horizon. Journal of Mathematical Analysis and Applications 321, 537-552.

Pilipovic, D. (2007). Energy risk: valuing and managing energy derivatives, second edition. McGraw-Hill, New York.

Plantinga, A. J. (1998). The optimal timber rotation: An option value approach. Forest Science 44, 192-202.

Pooley, D., P. Forsyth, and K. Vetzal (2003). Numerical convergence properties of option pricing pdes with uncertain volatility. IMA Journal of Numerical Analysis 23, 241-267.

Raymond, J. and R. Rich (1997). Oil and the macroeconomy: a markov state-switching approach. Journal of Money, Credit and Banking 29.

Reed, W. and H. Clarke (1990). Harvest decisions and asset valuation for biological resources exhibiting size-dependent stochastic growth. International Economic Review 31, 147-169.

Saphores, J.-D., L. Khalaf, and D. Pelletier (2002). On jump and arch effects in natural resource prices: An application to pacific northwest stumpage prices. American Journal of Agricultural Economics 84, 387-400.

Schwartz, E. (1997). The stochastic behavior of commodity prices: implications for valuation and hedging. Journal of Finance 52, 923-973.

Schwartz, E. and J. E. Smith (2000). Short-term variations and long-term dynamics in commodity prices. Management Science 46, 893-911.

Schwert, G. W. (1996). Markup pricing in mergers and acquisitions. Journal of Financial Economics 41, 153-192.

Smith, J. E. and K. F. McCardle (1998). Valuing oil properties: Integration option pricing and decision analysis approaches. Operation Research 46, 198-217.

Thomson, T. (1992). Optimal forest rotation when stumpage prices follow a diffusion process. Land Economics 68, 329-342. 
Varga, R. (2000). Matrix iterative analysis. Springer, New York.

Yin, R. and D. Newman (1995). A note on the tree-cutting problem in a stochastic environment. Journal of Forest Economics 1:2.

Yin, R. and D. Newman (1997). When to cut a stand of trees. Natural Resource Modeling 10, $251-61$.

Zvan, R., P. Forsyth, and K. Vezal (1998). A penalty method for american options with stochastic volatility. Journal of Computational and Applied Mathematics 91, 199-218.

\section{Appendix}

\section{A Relating P-measure and Q-measure parameters}

Parameter estimates in Section 5 are all Q-measure or risk-adjusted estimates. It is natural to want to relate these estimates to real-world or P-measure parameter values. We can determine the relation between Q-measure and P-measure estimates if we make an assumption for the price process in the P-measure. Assume that the spot price model in the P-measure for the RSMR case is comparable to the Q-measure model and is given by:

$$
d P=\alpha^{\prime}\left(s_{t}\right)\left(K^{\prime}\left(s_{t}\right)-P\right) d t+\sigma^{\prime}\left(s_{t}\right) P d Z
$$

where $s_{t}$ is a two-state continuous time Markov chain, taking two values 0 or 1 . The value of $s_{t}$ indicates the regime in which the lumber price resides at time $t$. Define a Poisson process $q^{s_{t} \rightarrow 1-s_{t}}$ with intensity $\lambda^{\left[s_{t} \rightarrow 1-s_{t}\right]}$. Then

$$
\begin{aligned}
d q^{s_{t} \rightarrow 1-s_{t}} & =1 \quad \text { with probability } \lambda^{\prime\left[s_{t} \rightarrow 1-s_{t}\right]} d t \\
& =0 \quad \text { with probability } 1-\lambda^{\prime\left[s_{t} \rightarrow 1-s_{t}\right]} d t
\end{aligned}
$$

Observe that in the above equations, we have defined P-measure parameters, $\alpha^{\prime}, K^{\prime}, \sigma^{\prime}$,and $\lambda^{\prime}$, to distinguish them from their counterparts in the Q-measure process.

Consider a futures contract on $P$, denoted $F\left(P, t, s_{t}\right)$ or just $F\left(s_{t}\right)$. Using Ito's lemma 
we can express $d F$ as:

$$
d F=\mu\left(s_{t}\right) d t+\sigma^{\prime}\left(s_{t}\right) P F\left(s_{t}\right)_{P} d Z+\Delta F d q^{s_{t} \rightarrow 1-s_{t}}
$$

where

$$
\begin{aligned}
\mu\left(s_{t}\right) & \equiv \alpha^{\prime}\left(s_{t}\right)\left(K^{\prime}\left(s_{t}\right)-P\right) F_{P}+\frac{\sigma^{\prime}\left(s_{t}\right)^{2} P^{2}}{2} F_{P P}+F_{t} \\
\Delta F & \equiv\left[F\left(1-s_{t}\right)-F\left(s_{t}\right)\right]
\end{aligned}
$$

To find the value of $F$ we create a hedging portfolio in the normal manner. Suppose we have three contracts, $F_{1}, F_{2}$ and $F_{3}$, which may be futures contracts with different maturities. We create a portfolio with these three securities choosing the quantity of each asset so that the portfolio is riskless. Following standard steps, this leads to the following condition that must hold under no-arbitrage assumptions for any contract $F(P, t)$ :

$$
\mu\left(s_{t}\right)=\beta_{P} \sigma^{\prime}\left(s_{t}\right) P F_{P}-\beta_{s w} \Delta F
$$

$\beta_{P}$ is the market price of risk for price diffusion risk and reflects the extra return over the risk free rate that the market requires for exposure to price risk. $\beta_{s w}$ is the market price of risk for regime switching. Both of these terms may depend on $P$ and $t$. Substituting in for $\mu\left(s_{t}\right)$ and $\Delta F$ gives

$$
\alpha^{\prime}\left(s_{t}\right)\left(K^{\prime}\left(S_{t}\right)-P\right) F_{P}+\frac{\sigma^{\prime}\left(s_{t}\right)^{2} P^{2}}{2} F_{P P}+F_{t}=\beta_{P} \sigma^{\prime}\left(s_{t}\right) P F_{P}-\beta_{s w}\left[F\left(1-s_{t}\right)-F\left(s_{t}\right)\right]
$$

Further rearranging results in:

$\alpha^{\prime}\left(s_{t}\right)\left(1+\frac{\beta_{P} \sigma^{\prime}\left(s_{t}\right)}{\alpha^{\prime}\left(s_{t}\right)}\right)\left(\frac{K^{\prime}\left(S_{t}\right)}{1+\frac{\beta_{P} \sigma^{\prime}\left(s_{t}\right)}{\alpha^{\prime}\left(s_{t}\right)}}-P\right) F_{P}+\frac{\sigma^{\prime}\left(s_{t}\right)^{2} P^{2}}{2} F_{P P}+F_{t}+\beta_{s w}\left[F\left(1-s_{t}\right)-F\left(s_{t}\right)\right]=0$

Equation (A7) describes the behaviour of a futures contract that depends on the stochastic variable $P$, in terms of the parameters defined in the P-measure, assuming the P-measure spot price is described by Equation (A1). Comparing Equation (A7) with Equation (8) we 
can see the relationship between P-measure and Q-measure parameters. In particular,

$$
\begin{aligned}
\alpha\left(s_{t}\right) & =\alpha^{\prime}\left(s_{t}\right)\left(1+\frac{\beta_{P} \sigma^{\prime}\left(s_{t}\right)}{\alpha^{\prime}\left(s_{t}\right)}\right) \\
K\left(s_{t}\right) & =\frac{K^{\prime}\left(s_{t}\right)}{1+\frac{\beta_{P} \sigma^{\prime}\left(s_{t}\right)}{\alpha^{\prime}\left(s_{t}\right)}} \\
\sigma\left(s_{t}\right) & =\sigma^{\prime}\left(s_{t}\right) \\
\lambda^{s_{t}\left(1-s_{t}\right)} & =\beta_{s w}
\end{aligned}
$$

For further comparison we make assumptions regarding the signs of the parameters in the above equations. We know that $\sigma^{\prime}\left(s_{t}\right)>0$. For the other two parameters the most likely case is that $\beta_{P}$ and $\alpha^{\prime}\left(s_{t}\right)$ are also positive. In this case it follows that $\alpha\left(s_{t}\right)>\alpha^{\prime}\left(s_{t}\right)$ and $K\left(s_{t}\right)<K^{\prime}\left(s_{t}\right)$. It makes intuitive sense that in moving from the real world to the risk neutral world, the risk adjustment implies a more rapid speed of mean reversion and a lower long run equilibrium level. Optimal actions are taken by assuming that lumber prices revert to a lower long run mean and at a faster rate than is actually the case.

Rearranging Equations (A8) and (A9), the mean reversion rate and the long run equilibrium price level under the P-measure, $\alpha^{\prime}\left(s_{t}\right)$ and $K^{\prime}\left(S_{t}\right)$, can be expressed as:

$$
\begin{aligned}
\alpha^{\prime}\left(s_{t}\right) & =\alpha\left(s_{t}\right)-\beta_{P} \sigma\left(s_{t}\right) \\
K^{\prime}\left(s_{t}\right) & =\left(1+\frac{\beta_{P} \sigma^{\prime}\left(s_{t}\right)}{\alpha^{\prime}\left(s_{t}\right)}\right) K\left(s_{t}\right)
\end{aligned}
$$

Based on the calibrated parameters presented in Tables 2 and 3, it can be seen from Equation (A12) that given a small positive $\beta_{P}, \alpha^{\prime}(0)>\alpha^{\prime}(1)$. Hence Equation (A13) implies that the high price regime in the real world is also the high price regime in the risk neutral world, i.e. $K^{\prime}(0)<K^{\prime}(1)$.

Equation (A10) tells us that volatility is the same in the $\mathrm{P}$ and $\mathrm{Q}$ measures. Equation (A11) tells us that the intensity of regime switching, $\lambda^{s_{t} \rightarrow\left(1-s_{t}\right)}$, is equal to the market price of risk of regime switching. Hence the risk-adjusted probability of switching regimes $\lambda^{s_{t} \rightarrow\left(1-s_{t}\right)} d t$ may be quite different from the actual probability, $\lambda^{\prime} d t$, as implied by historical price data. 


\section{B Numerical solution of HJB Variational Inequality}

The basic linear complementarity problem of our optimal tree harvesting problem can be expressed as Equation (28)

$$
\begin{array}{r}
V\left(s_{t}\right)_{\tau}-V\left(s_{t}\right)_{\alpha}=\alpha\left(s_{t}\right)\left(K\left(s_{t}\right)-P\right) V\left(s_{t}\right)_{P}+\frac{1}{2}\left(\sigma\left(s_{t}\right) P\right)^{2} V\left(s_{t}\right)_{P P}-r V\left(s_{t}\right)+ \\
\lambda^{s_{t} \rightarrow 1-s_{t}}\left(V\left(1-s_{t}\right)-V\left(s_{t}\right)\right)+\Upsilon\left(s_{t}\right)
\end{array}
$$

This PDE is discretized using unequally spaced grids in the directions of $P$ and $\alpha$. Time direction is also discretized. Define nodes on the axes for $P, \alpha$ and $\tau$ by

$$
\begin{aligned}
P & =\left[P_{1}, P_{2}, \ldots, P_{I}\right] \\
\alpha & =\left[\alpha_{1}, \alpha_{2}, \ldots, \alpha_{J}\right] \\
\tau & =\left[\tau_{1}, \tau_{2}, \ldots, \tau_{N}\right]
\end{aligned}
$$

Using fully implicit difference method, the difference scheme for Equation (B1) can be written as

$$
\begin{array}{r}
\frac{V\left(s_{t}, P_{i}, \alpha_{j}, \tau^{n+1}\right)-V\left(s_{t}, P_{i}, \alpha_{j+\Delta \tau}, \tau^{n}\right)}{\Delta \tau}=\left[\alpha\left(s_{t}\right)\left(K\left(s_{t}\right)-P\right) V\left(s_{t}\right)_{P}+\frac{1}{2}\left(\sigma\left(s_{t}\right) P\right)^{2} V\left(s_{t}\right)_{P P}-r V\left(s_{t}\right)+\right. \\
\left.\lambda^{s_{t} \rightarrow 1-s_{t}}\left(V\left(1-s_{t}\right)-V\left(s_{t}\right)\right)+\Upsilon\left(s_{t}\right)\right]_{i j}^{n+1}(\mathrm{~B} 3)
\end{array}
$$

For simplicity, define $V\left(s_{t}\right)_{i j}^{n+1}=V\left(s_{t}, P_{i}, \alpha_{j}, \tau^{n+1}\right), V^{*}\left(s_{t}\right)_{i j}^{n}=V\left(s_{t}, P_{i}, \alpha_{j+\Delta \tau}, \tau^{n}\right)$ and rewrite Equation (B3) as

$$
\begin{array}{r}
\frac{V\left(s_{t}\right)_{i j}^{n+1}-V^{*}\left(s_{t}\right)_{i j}^{n}}{\Delta \tau}=\left[\alpha\left(s_{t}\right)\left(K\left(s_{t}\right)-P\right) V\left(s_{t}\right)_{P}+\frac{1}{2}\left(\sigma\left(s_{t}\right) P\right)^{2} V\left(s_{t}\right)_{P P}-r V\left(s_{t}\right)+\right. \\
\left.\lambda^{s_{t} \rightarrow 1-s_{t}}\left(V\left(1-s_{t}\right)-V\left(s_{t}\right)\right)+\Upsilon\left(s_{t}\right)\right]_{i j}^{n+1}
\end{array}
$$

Since the right hand side of Equation (B4) only contains the state variable $P$, this onedimensional PDE is solved numerically for each stand age $\alpha_{j}$ within each time step. After 
one time step iteration completes, using linear interpolation to get $V\left(s_{t}, P_{i}, \alpha_{j+\Delta \tau}, \tau^{n}\right)$. Hence our only concern is the discretization of derivatives with respect to $P$.

\section{B1 Discretization for interior points along $P$ direction}

For simplicity, the dependence of the regime $s_{t}$ is dropped for discretization, except for $V\left(1-s_{t}\right)$ in Equation (B4). Hence it can be further simplified as

$$
\frac{V_{i j}^{n+1}-V_{i j}^{* n}}{\Delta \tau}=\left[\alpha(K-P) V_{P}+\frac{1}{2}(\sigma P)^{2} V_{P P}-r V+\lambda^{s_{t} \rightarrow 1-s_{t}}\left(V\left(1-s_{t}\right)-V\right)+\Upsilon\right]_{i j}^{n+1}
$$

Central difference, forward difference and backward difference methods can be used to discretize the first derivative term $V_{P}$ for interior points $i=[2, \ldots, I-1]$. We choose the difference method which will assure the positive coefficient scheme. If all these three methods can guarantee the positive coefficient scheme, central difference will be picked up for its faster convergence. For illustration purpose, the complete discretization equation will use central difference method for $V_{P}$.

$$
\begin{aligned}
& \frac{V_{i j}^{n+1}-V_{i j}^{* n}}{\Delta \tau}=\left\{\frac{\sigma^{2} P^{2}}{2}\left[\frac{\frac{V_{i+1, j}-V_{i j}}{P_{i+1}-P_{i}}-\frac{V_{i j}-V_{i-1, j}}{P_{i}-P_{i-1}}}{\frac{P_{i+1}-P_{i-1}}{2}}\right]+\alpha(K-P)\left[\frac{V_{i+1, j}-V_{i-1, j}}{P_{i+1}-P_{i-1}}\right]\right. \\
& \left.-\left(r+\lambda^{s_{t} \rightarrow 1-s_{t}}\right) V_{i j}+\lambda^{s_{t} \rightarrow 1-s_{t}} V\left(1-s_{t}\right)_{i j}+\frac{\overline{\pi_{i j}}}{\Delta \tau}\left[\left(P_{i}-C\right) Q_{j}+V_{i 0}-V_{i j}\right]\right\}^{n+1}
\end{aligned}
$$

Equation (B6) can be simplified as

$$
\begin{aligned}
\frac{V_{i j}^{n+1}-V_{i j}^{* n}}{\Delta \tau}= & a_{i} V_{i-1, j}^{n+1}+b_{i} V_{i+1, j}^{n+1}-\left[a_{i}+b_{i}+r+\lambda^{s_{t} \rightarrow 1-s_{t}}+\frac{\overline{\pi_{i j}}}{\Delta \tau}\right] V_{i j}^{n+1} \\
& +\lambda^{s_{t} \rightarrow 1-s_{t}} V\left(1-s_{t}\right)_{i j}^{n+1}+\frac{\overline{\pi_{i j}}}{\Delta \tau}\left[\left(P_{i}-C\right) Q_{j}+V_{i 0}-V_{i j}^{n+1}\right]
\end{aligned}
$$

where define $\alpha_{i} \equiv \frac{\sigma^{2} P_{i}^{2}}{P_{i+1}-P_{i-1}}$ 


\section{For central difference method}

$$
a_{i} \equiv \frac{\alpha_{i}}{P_{i}-P_{i-1}}-\frac{\alpha\left(K-P_{i}\right)}{P_{i+1}-P_{i-1}} ; \quad b_{i} \equiv \frac{\alpha_{i}}{P_{i+1}-P_{i}}+\frac{\alpha\left(K-P_{i}\right)}{P_{i+1}-P_{i-1}}
$$

\section{For forward difference method}

$$
a_{i} \equiv \frac{\alpha_{i}}{P_{i}-P_{i-1}} ; \quad b_{i} \equiv \frac{\alpha_{i}}{P_{i+1}-P_{i}}+\frac{\alpha\left(K-P_{i}\right)}{P_{i+1}-P_{i}}
$$

\section{For backward difference method}

$$
a_{i} \equiv \frac{\alpha_{i}}{P_{i}-P_{i-1}}-\frac{\alpha\left(K-P_{i}\right)}{P_{i}-P_{i-1}} ; \quad b_{i} \equiv \frac{\alpha_{i}}{P_{i+1}-P_{i}}
$$

\section{B2 Discretization of boundary conditions for $i=1$ and $i=I$}

When $P=0$, no specific boundary condition is needed. Substitute $P=0$ into HJB Equation (B1) to get PDE for this boundary

$$
V\left(s_{t}\right)_{\tau}-V\left(s_{t}\right)_{\varphi}=\alpha\left(s_{t}\right) K\left(s_{t}\right) V\left(s_{t}\right)_{P}-r V\left(s_{t}\right)+\lambda^{s_{t} \rightarrow 1-s_{t}}\left(V\left(1-s_{t}\right)-V\left(s_{t}\right)\right)+\Upsilon\left(s_{t}\right)
$$

Using forward discretization for $V\left(s_{t}\right)_{P}$, the discrete version of Equation (B8) can be written as

$$
\begin{array}{r}
\frac{V_{1 j}^{n+1}-V_{1 j}^{* n}}{\Delta \tau}=b_{1} V_{2, j}^{n+1}-\left[b_{1}+r+\lambda^{s_{t} \rightarrow 1-s_{t}}+\frac{\overline{\pi_{1 j}}}{\Delta \tau}\right] V_{1 j}^{n+1}+\lambda^{s_{t} \rightarrow 1-s_{t}} V\left(1-s_{t}\right)_{1 j}^{n+1}+ \\
\frac{\overline{\pi_{1 j}}}{\Delta \tau}\left[\left(P_{1}-C\right) Q_{j}+V_{10}-V_{1 j}^{n+1}\right]
\end{array}
$$

where $b_{1}=\frac{\alpha K}{P_{1}-P_{0}}$.

When $P=P_{I}$, the option value is a linear function of the price. Hence the second derivative term $V\left(s_{t}\right)_{P P}=0$. Guess the solution $V\left(s_{t}\right)_{I j}=A(\tau)+B(\tau) P_{I}$. When $P \rightarrow \infty$, the term $B(\tau) P_{I}$ dominates and $V\left(s_{t}\right)_{I j} \approx B(\tau) P_{I}$. For the first derivative term

$\alpha\left(s_{t}\right)\left(K\left(s_{t}\right)-P\right) V\left(s_{t}\right)_{P}, P_{I} \gg K\left(s_{t}\right)$. Hence $\alpha\left(s_{t}\right)\left(K\left(s_{t}\right)-P\right) V\left(s_{t}\right)_{P} \approx-\alpha\left(s_{t}\right) P V\left(s_{t}\right)_{P}=$ 
$-\alpha\left(s_{t}\right) V\left(s_{t}\right)$. The HJB equation (B1) in this boundary can then be expressed as

$$
V\left(s_{t}\right)_{\tau}-V\left(s_{t}\right)_{\varphi}=-\alpha\left(s_{t}\right) V\left(s_{t}\right)-r V\left(s_{t}\right)+\lambda^{s_{t} \rightarrow 1-s_{t}}\left(V\left(1-s_{t}\right)-V\left(s_{t}\right)\right)+\Upsilon\left(s_{t}\right)
$$

The discrete version of Equation (B10) can be written as

$$
\begin{aligned}
\frac{V_{I j}^{n+1}-V_{I j}^{* n}}{\Delta \tau}=-\left[\alpha+r+\lambda^{s_{t} \rightarrow 1-s_{t}}+\frac{\overline{\pi_{I j}}}{\Delta \tau}\right] & V_{I j}^{n+1}+\lambda^{s_{t} \rightarrow 1-s_{t}} V\left(1-s_{t}\right)_{I j}^{n+1}+ \\
& \frac{\overline{\pi_{I j}}}{\Delta \tau}\left[\left(P_{I}-C\right) Q_{j}+V_{I 0}-V_{I j}^{n+1}\right]
\end{aligned}
$$

\section{B3 Complete discretization}

Combine Equations (B7), (B9) and (B11), and write them in matrix form as

$$
\begin{array}{r}
{\left[\left(1+\Delta \tau\left(r+\lambda^{s_{t} \rightarrow 1-s_{t}}\right)\right) I+W\left(s_{t}\right)+\bar{\pi}^{n+1}\right] V\left(s_{t}\right)^{n+1}-\Delta \tau \lambda^{s_{t} \rightarrow 1-s_{t}} V\left(1-s_{t}\right)^{n+1}=} \\
V\left(s_{t}\right)^{* n}+{\overline{\pi\left(s_{t}\right.}}^{n+1}\left[(P-C) Q+V\left(s_{t}\right)_{0}^{n+1}\right]
\end{array}
$$

where $W\left(s_{t}\right)$ is a square sparse matrix which has the following elements:

$W\left(s_{t}\right)=\left[\begin{array}{cccccccc}\Delta \tau b_{1} & -\Delta \tau b_{1} & 0 & 0 & 0 & \ldots & 0 & 0 \\ -\Delta \tau a_{2} & \Delta \tau\left(a_{2}+b_{2}\right) & -\Delta \tau b_{2} & 0 & 0 & \ldots & 0 & 0 \\ \ldots & \ldots & \ldots & \ldots & \ldots & \ldots & \ldots & \ldots \\ 0 & 0 & 0 & \ldots & 0 & -\Delta \tau a_{I-1} & \Delta \tau\left(b_{I-1}+b_{I-1}\right) & -\Delta \tau a_{I-1} \\ 0 & 0 & 0 & \ldots & 0 & 0 & 0 & \Delta \tau \alpha\left(s_{t}\right)\end{array}\right]$

The above analysis for the option value in regime $s_{t}$ can be used in the same way for the option value in the other regime $1-s_{t}$. The similar equation as Equation (B12) can be 
derived for $V\left(1-s_{t}\right)$ which can be written as

$$
\begin{array}{r}
{\left[\left(1+\Delta \tau\left(r+\lambda^{1-s_{t} \rightarrow s_{t}}\right)\right) I+W\left(1-s_{t}\right)+\bar{\pi}^{n+1}\right] V\left(1-s_{t}\right)^{n+1}-\Delta \tau \lambda^{1-s_{t} \rightarrow s_{t}} V\left(s_{t}\right)^{n+1}=} \\
V\left(1-s_{t}\right)^{* n}+\overline{\pi\left(1-s_{t}\right)}{ }^{n+1}\left[(P-C) Q+V\left(1-s_{t}\right)_{0}^{n+1}\right]
\end{array}
$$

Denote $A A\left(s_{t}\right)=\left[\left(1+\Delta \tau\left(r+\lambda^{s_{t} \rightarrow 1-s_{t}}\right)\right) I+W\left(s_{t}\right)+\bar{\pi}^{n+1}\right]$. Then its counterpart for regime $1-s_{t}$ can be defined as $A A\left(1-s_{t}\right)=\left[\left(1+\Delta \tau\left(r+\lambda^{1-s_{t} \rightarrow s_{t}}\right)\right) I+W\left(1-s_{t}\right)+\bar{\pi}^{n+1}\right]$. Stack Equations (B12) and (B14) together and get

$$
\begin{gathered}
{\left[\begin{array}{cc}
A A\left(s_{t}\right) & -\Delta \tau \lambda^{s_{t} \rightarrow 1-s_{t}} \\
-\Delta \tau \lambda^{1-s_{t} \rightarrow s_{t}} & A A\left(1-s_{t}\right)
\end{array}\right]\left[\begin{array}{c}
V\left(s_{t}\right) \\
V\left(1-s_{t}\right)
\end{array}\right]^{n+1}=\left[\begin{array}{c}
V^{*}\left(s_{t}\right) \\
V^{*}\left(1-s_{t}\right)
\end{array}\right]^{n}+} \\
{\left[\frac{\overline{\pi\left(s_{t}\right)}}{\overline{\pi\left(1-s_{t}\right)}}\right]^{n+1}\left[\begin{array}{c}
\text { payof } f\left(s_{t}\right) \\
\text { payof } f\left(1-s_{t}\right)
\end{array}\right]^{n+1}}
\end{gathered}
$$

where $Z_{\text {matrix }}=\left[\begin{array}{cc}A A\left(s_{t}\right) & -\Delta \tau \lambda^{s_{t} \rightarrow 1-s_{t}} \\ -\Delta \tau \lambda^{1-s_{t} \rightarrow s_{t}} & A A\left(1-s_{t}\right)\end{array}\right]$.

\section{Convergence to the viscosity solution}

In this appendix, the monotonicity and stability properties of the discrete equations in our numerical scheme are analyzed. We claimed earlier that our scheme is consistent. A discretization that is consistent, monotone, and stable will converge to the viscosity solution.

Before proving the monotonicity and stability of our scheme, it is useful to gather together several results for the finite difference discretization.

Lemma C.1. $Z_{\text {matrix }}$ is an $M$ matrix $^{29}$

Proof. Equation (31) is discretized using central difference, forward difference or backward difference methods to get a positive coefficient discretizations. The positive coefficient discretization means that $Z_{\text {matrix }}$ has non-positive offdiagonal elements. Moreover, the sum of

\footnotetext{
${ }^{29}$ For definition and properties of $M$ matrix, see Varga (2000).
} 
all elements in each row of $Z_{\text {matrix }}$ is non-negative ${ }^{30}$. Hence $Z_{\text {matrix }}$ is an $M$ matrix.

We follow d'Halluin et al. (2005)'s definition of monotone discretizations and rewrite the discrete Equation $(28)$ at each pair of node $\left(P_{i}, \varphi_{j}\right) \mathrm{as}^{31}$

$$
\begin{aligned}
g_{i j}\left(V_{i j}^{n+1},\left\{V_{i^{-} j}^{n+1}\right\},\left\{V^{n}\right\}\right) & =-\left[Z V_{j}^{n+1}\right]_{i}+\left[\Phi^{n+1} V^{n}\right]_{i j}+\left[\bar{\pi}^{n+1}\right]_{i i}\left(\text { payoff }_{i j}-V_{i j}^{n+1}\right) \\
& =0
\end{aligned}
$$

where $\left\{V_{i^{-}, j}^{n+1}\right\}$ denotes the set of values $V_{i^{-}, j}^{n+1}$ without the $i$ th element $V_{i j}^{n+1} . \Phi^{n+1}$ in this expression is the Lagrange linear interpolant operator ${ }^{32}$ used to deal with linear interpolation in the semi-lagrangian method.

$$
\left[\Phi^{n+1} V^{n}\right]_{i j}=V\left(s_{t}, P_{i}, \varphi_{j+\Delta \tau}, \tau^{n}\right)+\text { interpolation error }
$$

Theorem C.2. The discretization scheme (C1) is unconditionally monotone.

Proof. In Lemma C.1 we have already showed that $Z$ is an $M$-matrix. Therefore, $-\left[Z V_{j}^{n+1}\right]_{i}$ is a strictly decreasing function of $V_{i j}^{n+1}$, and a non-decreasing function of $\left\{V_{i^{-}, j}^{n+1}\right\}$. $\left[\Phi^{n+1} V^{n}\right]_{i j}$ is a non-decreasing function of $\left\{V^{n}\right\}$, since $\Phi^{n+1}$ is a linear interpolant operator. The last term in equation $(\mathrm{C} 1)\left[\bar{\pi}^{n+1}\right]_{i i}\left(\right.$ payof $\left.f_{i j}-V_{i j}^{n+1}\right)$ is a non-increasing function of $V_{i j}^{n+1}$ since the elements in $\left[\bar{\pi}^{n+1}\right]_{i i}$ are non-negative. Therefore, this discretization scheme is monotone based on d'Halluin et al. (2005)'s definition.

Theorem C.3. The scheme satisfies

$$
\left\|V^{n+1}\right\|_{\infty} \leq \max \left\{\left\|V^{n}\right\|_{\infty}, \| \text { payoff } \|_{\infty}\right\}
$$

and is unconditionally stable.

\footnotetext{
${ }^{30}$ This can be checked from detailed discretization in Appendix.

${ }^{31}$ For simplicity, in this expression $V \equiv V\left(s_{t}\right)$ or $V \equiv V\left(1-s_{t}\right)$.

${ }^{32}$ For details about Lagrange linear interpolation operator, seed'Halluin et al. (2005).
} 
Proof. Write out the complete discretized version of Equation (28) as

$$
\begin{array}{r}
-\Delta \tau V\left(s_{t}\right)_{i-1, j}^{n+1}+\left[1+\Delta \tau\left(a\left(s_{t}\right)_{i}+b\left(s_{t}\right)_{i}+r+\lambda^{k \rightarrow 1-k}\right)+\overline{\pi\left(s_{t}\right)_{i j}^{n+1}}\right] V\left(s_{t}\right)_{i j}^{n+1}-\Delta \tau b\left(s_{t}\right)_{i} V\left(s_{t}\right)_{i+1, j}^{n+1} \\
-\Delta \tau \lambda^{k \rightarrow 1-k} V\left(1-s_{t}\right)_{i j}^{n+1}=\sum_{i j} w_{i j} V\left(s_{t}\right)_{i j}^{n}+\overline{\pi\left(s_{t}\right)_{i j}^{n+1}} \operatorname{payof}_{i}(\mathrm{C} 2
\end{array}
$$

where $w_{i j}$ is linear interpolant weight, satisfying $0 \leq w_{i j} \leq 1$ and $\sum w_{i j}=1 . a\left(s_{t}\right)_{i}$ and $b\left(s_{t}\right)_{i}{ }^{33}$ are the components in $Z$ matrix, which are non-negative. Denote $\left|V\left(s_{t}\right)_{m, j}^{n+1}\right|=$ $\left\|V_{j}^{n+1}\right\|_{\infty}$ where $m$ is an index. Equation (C2) implies that

$$
\left\|V_{j}^{n+1}\right\|_{\infty}\left(1+r \Delta \tau+\bar{\pi}_{m m}\right) \leq\left\|V^{n}\right\|_{\infty}+\bar{\pi}_{m m} \| \text { payoff } \|
$$

which can be further simplified as

$$
\left\|V_{j}^{n+1}\right\|_{\infty}\left(1+r \Delta \tau+\bar{\pi}_{m m}\right) \leq \max \left\{\left\|V^{n}\right\|_{\infty}, \| \text { payof } f \|_{\infty}\right\}\left(1+\bar{\pi}_{m m}\right)
$$

Rearrange Equation (C3)

$$
\left\|V_{j}^{n+1}\right\|_{\infty} \leq \max \left\{\left\|V^{n}\right\|_{\infty}, \| \text { payof } f \|_{\infty}\right\} \frac{\left(1+\bar{\pi}_{m m}\right)}{\left(1+r \Delta \tau+\bar{\pi}_{m m}\right)}
$$

Hence just as claimed, we get

$$
\left\|V^{n+1}\right\|_{\infty} \leq \max \left\{\left\|V^{n}\right\|_{\infty}, \| \text { payof } f \|_{\infty}\right\}
$$

and the scheme is unconditionally stable

\footnotetext{
${ }^{33}$ The detail expression is in Appendix.
} 